\title{
Eleição de Dilma ou segunda reeleição de Lula? Uma análise espacial do pleito de 2010
}

\author{
André Matos Magalhães \\ Marcelo Eduardo Alves da Silva \\ Fernando de Mendonça Dias
}

\section{Introdução}

Diversos trabalhos buscaram entender o perfil do eleitorado de Lula e as mudanças ocorridas entre as eleições de 2002 e $2006^{1}$. Muito foi dito a respeito da mudança do seu eleitorado entre as duas eleições e como o Bolsa Família teria atuado nesse sentido. O eleitor de Lula teria mudado de um perfil mais diversificado (várias regiões do país, diferentes classes sociais, graus de instrução distintos) para um perfil mais específico ligado ao seu principal programa social (Bolsa Família) e mais concentrado no Norte e Nordeste, em uma população mais pobre e menos escolarizada ${ }^{2}$.

Em 2010, impossibilitado de concorrer ao terceiro mandato, Lula lançou como sua candidata Dilma Rousseff, alguém que nunca tinha disputado uma eleição. O pleito eleitoral daquele ano acabou por confirmar a eleição da candidata da situação, que, apoiada pelo ex-presidente Lula e com a força do governo federal, foi eleita em dois turnos. Por razões claras, a vitória da atual presidente foi então atribuída à força do expresidente Lula e ao principal programa social do seu governo, o Bolsa Família ${ }^{3}$.

No presente artigo nós analisamos os dados da eleição de 2010 buscando identificar os fatores mais importantes que contribuíram para os percentuais obtidos pelos principais candidatos. Em particular, nosso objetivo é entender qual foi a importância do apoio de Lula e qual o peso do Bolsa Família. Além disso, buscamos compreender qual o perfil do eleitor de Marina em 2010 e como isso poderia influenciar no pleito de 2014.

Como esperado, os resultados indicam um forte efeito conjunto do Bolsa Família e do ex-presidente Lula para as votações recebidas por Dilma no primeiro e segundo turnos. Além disso, o Bolsa Família teve efeito negativo para Marina. Um efeito interessante observado nas regressões é a confirmação do perfil do eleitor de Marina

\footnotetext{
${ }^{1}$ Ver, por exemplo, Hunter e Power (2007); Soares e Terron (2008); Canêdo-Pinheiro (2009).

2 Soares et al. (2006) e Nicolau e Peixoto (2007), por exemplo.

${ }^{3} \mathrm{Em}$ 2014, Dilma enfrentou a sua segunda disputa eleitoral e se lançou à reeleição contra candidatos que ainda não haviam disputado a presidência da República. A chapa do PSDB apresentou o senador Aécio Neves e o PSB, a ex-senadora Marina Silva, que concorrera contra Dilma em 2010. Na primeira versão do artigo o candidato do PSB ainda era, no entanto, o ex-governador de Pernambuco, Eduardo Campos.
} 
Silva. A sua participação esteve positivamente relacionada aos evangélicos, nos municípios mais adensados, com maior desigualdade de renda e menor taxa de analfabetismo. Esse seria potencialmente o eleitorado que poderia aderir à candidatura da Rede na eleição de 2014 caso Marina houvesse entrado desde o começo como candidata independente.

Nas próximas seções são apresentados uma breve discussão a respeito dos trabalhos anteriores, que tratam do perfil do eleitorado de Lula e da importância do Bolsa Família, um resumo dos dados utilizados, a estratégia empírica e os resultados. A última seção apresenta as conclusões do artigo.

\section{O Bolsa Família e a eleição de 2006}

Criado em 2003 para unificar e ampliar os programas de transferência de renda do governo federal ${ }^{4}$, o Bolsa família transformou-se rapidamente na principal bandeira da primeira gestão de Lula. Atuando em todas as unidades da federação, o programa beneficia atualmente aproximadamente 11 milhões de famílias (aqueles com renda per capita mensal inferior a $\mathrm{R} \$ 70,00)$. Um ponto positivo do programa é a condicionalidade para recebimento dos recursos, especialmente nos casos de famílias com crianças: para receber o benefício, as famílias devem manter as crianças na escola, monitorar sua nutrição e sua vacinação e acompanhar as gestantes. Outro ponto importante do programa é que para participar, além de satisfazer os critérios de elegibilidade, basta ser cadastrado pelo município, sem intermediações políticas ${ }^{5}$.

Por sua dimensão e seu foco, a correlação entre o programa e a redução da pobreza e da desigualdade observadas no país foi amplamente estudada. Em conjunto com os aumentos reais de salário mínimo, o Bolsa Família acabou tendo impacto positivo na redução da pobreza ${ }^{6}$.

Como então não perguntar qual foi o efeito eleitoral do Programa Bolsa Família? A reeleição de Lula em 2006 levantou essa questão a respeito do papel do principal programa social do seu governo no seu desempenho eleitoral. O questionamento a respeito da força do programa e do seu impacto na votação final era apenas natural. A dimensão do programa e a sua capilaridade deram ao governo a capacidade de chegar aos lares da população mais pobre do país, em todas as regiões, colocando renda

\footnotetext{
${ }^{4}$ Os principais programas anteriores ao Bolsa Família eram o Programa Bolsa Escola, o Programa Cartão Alimentação, o Programa Bolsa Alimentação e o Programa Auxílio-Gás.

${ }^{5}$ Hunter e Power (2007) observam que esse é um aspecto importante do programa e que o difere do clientelismo tradicional dos programas sociais nacionais. Não há qualquer critério político para o cadastramento do cidadão no Cadastro Único. Nesse caso, não há penalidades diretas para o beneficiário que venha a votar contra o governo. Cabe notar que do ponto de vista político nada impede o uso do discurso de que a oposição irá acabar com o programa caso venha a ser eleita. Isso pode ter efeitos no voto final.

${ }^{6}$ Ver, por exemplo, Soares (2012).
} 
mensalmente nas mãos dessas famílias.

Ao mesmo tempo, a análise dos dados das votações indicava que o perfil do eleitor de Lula tinha se alterado entre 2002 e 2006, passando de uma distribuição mais ampla no país para uma maior concentração nas áreas mais pobres. Ou seja, nas áreas dos beneficiários do programa. As Figuras 1 e 2 a seguir ilustram essa mudança. Seria essa uma coincidência?

Figura 1

Distribuição dos votos de Lula no segundo turno de 2002 como proporção do total de votos válidos

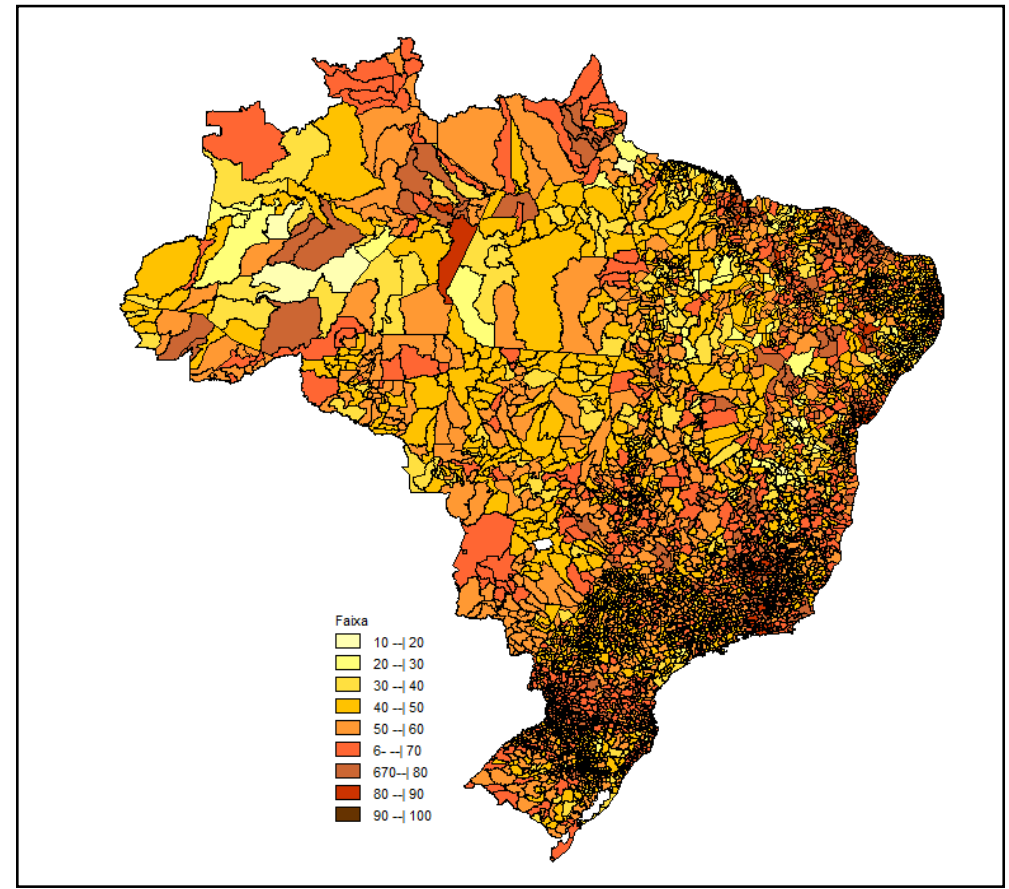

Fonte: Elaboração própria a partir de dados do TSE.

Para Nicolau e Peixoto (2007), o efeito do Bolsa Família sobre o voto em Lula em 2006 foi claro. Apesar de alcançar os mesmos 61\% de votos válidos em 2006 e 2002, os autores notam que, na reeleição, o perfil do seu eleitor era muito distinto daquele observado na primeira eleição. Em particular, em municípios com melhores indicadores sociais, Lula obteve, em média, maior votação em 2002. Já em 2006 o efeito foi exatamente o inverso. Os autores atribuem tal mudança ao perfil dos beneficiários do programa (famílias de baixa renda, principalmente concentradas nos municípios pobres do Norte e Nordeste) e ao volume de recursos aplicados.

Hunter e Power (2007) também analisam o desempenho eleitoral de Lula em 2006 com foco na mudança da base eleitoral do ex-presidente. Eles observam que Lula 
perdeu votos dos eleitores mais ricos e instruídos e passou a receber votos dos eleitores com menor nível de educação. Os autores identificam ainda que Lula se saiu melhor do que o PT em 2006, especialmente nos estados de IDH mais baixo. Eles atribuem esse efeito à força do Programa Bolsa Família. Efeito semelhante foi apontado por Soares e Terron (2008). Esses autores concluem que a participação do Programa Bolsa Família sobre a renda local foi um determinante desse novo contorno das bases geoeleitorais e o fator com maior peso na explicação da votação municipal em 2006.

Figura 2

Distribuição dos votos de Lula no segundo turno de 2006 como proporção do total de votos válidos

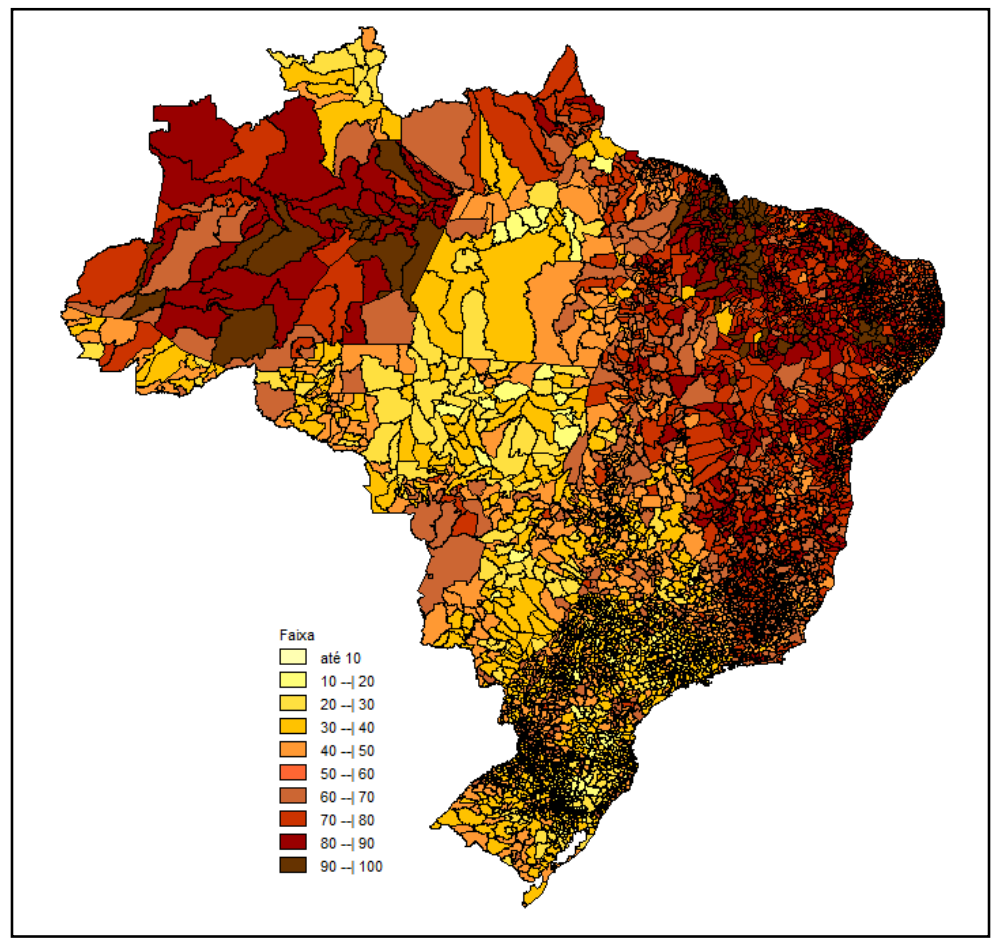

Fonte: Elaboração própria a partir de dados do TSE.

Outro artigo que aborda o tema é o de Shikida et al. (2009). Usando uma abordagem espacial, os autores corroboram a mudança no perfil da votação de Lula para maior concentração em municípios menos desenvolvidos observados em outros artigos. O trabalho, entretanto, conclui que não existem claras indicações sobre a importância do Bolsa Família para a vitória de Lula em 2006. A vitória estaria mais relacionada aos resultados positivos da economia do que ao programa social. Ou seja, a inflação baixa, o crescimento do mercado de trabalho, a redução das desigualdades e o aumento do salário real seriam mais importantes do que o Bolsa Família na definição do voto do 
eleitor.

Dentro da mesma temática, Canêdo-Pinheiro (2009) investiga os determinantes da mudança no perfil do eleitorado de Lula entre as eleições de 2002 e 2006 focando, em particular, no papel desempenhado pelo Programa Bolsa Família e pelo crescimento econômico verificado nos municípios brasileiros durante o primeiro mandato do expresidente. Um resultado interessante foi mostrar que, diferentemente de Shikida et al. (2009), os efeitos do programa foram superiores aos do desempenho da economia como fator explicativo do desempenho eleitoral de Lula no pleito de 2006. Contudo, como destacado pelo autor, nenhum dos dois elementos foi capaz de explicar as razões da mudança no padrão de votação entre os dois pleitos, o que sugere, segundo CanêdoPinheiro, que o incumbente naturalmente teria resultado superior em municípios mais pobres e mais dependentes do Estado.

O artigo de Zucco (2013) é o primeiro a tratar de três eleições presidenciais consecutivas nas quais um programa de transferência de renda esteve presente. 0 trabalho faz uso tanto de dados agregados como individuais e, pelo período coberto, conseguiu analisar os efeitos eleitorais com dois partidos distintos como incumbentes (PSDB e PT). A principal conclusão do autor é a de que programas de transferência de renda no Brasil têm efeitos eleitorais positivos, ajudando na votação do partido no poder, mas esses efeitos são de curto prazo e não geram alinhamentos ou fidelidades de longo prazo a políticos ou partidos.

Marzagão (2013) se propõe a analisar a distribuição geográfica dos votos de Dilma em 2010. A principal preocupação do autor é tentar explicar o que causaria os padrões geográficos observados, quais sejam, percentuais maiores de votos no Nordeste e Norte e menores no Sul e Sudeste do país (ver Figuras 3 e 4 a seguir). Ele propõe três hipóteses: (a) uma verdadeira interação espacial por vias econômicas e interações entre municípios próximos; (b) fatores limitados de campanha que levam ao maior esforço em algumas áreas e não em todos os municípios; e (c) os percentuais de votos são espacialmente agrupados porque municípios próximos são socioeconomicamente semelhantes e teriam preferências políticas semelhantes. Ou seja, o comportamento do eleitor seria influenciado por condições materiais e essas condições estão espacialmente agrupadas.

O próprio autor argumenta que, enquanto a confirmação da hipótese (a) indicaria uma verdadeira interação entre os municípios, as hipóteses (b) e (c) estariam mais relacionadas à omissão de variáveis que pudessem captar a verdadeira dimensão espacial dos votos. Ou seja, (a) significaria que o modelo correto seria o de autocorrelação espacial, com um problema de viés para os coeficientes estimados. Por outro lado, (b) e (c) implicariam um modelo de erro espacial, no qual o problema seria a eficiência das estimações.

Marzagão (2013) segue então para testar as suas hipóteses. Ele apresenta claras 
evidências de padrões espaciais dos votos para Dilma, semelhantes aos encontrados para Lula em 2006, estimando os modelos de erro e autocorrelação espacial. A sua conclusão é de que as evidências suportam a hipótese (b), qual seja, as campanhas apresentam um padrão espacial que acaba por se refletir nos resultados finais. A falta de uma variável que possa captar tal efeito leva à presença da dependência espacial observada nos dados.

Figura 3

Distribuição dos votos de Dilma no primeiro turno de 2010 como proporção do total de votos válidos

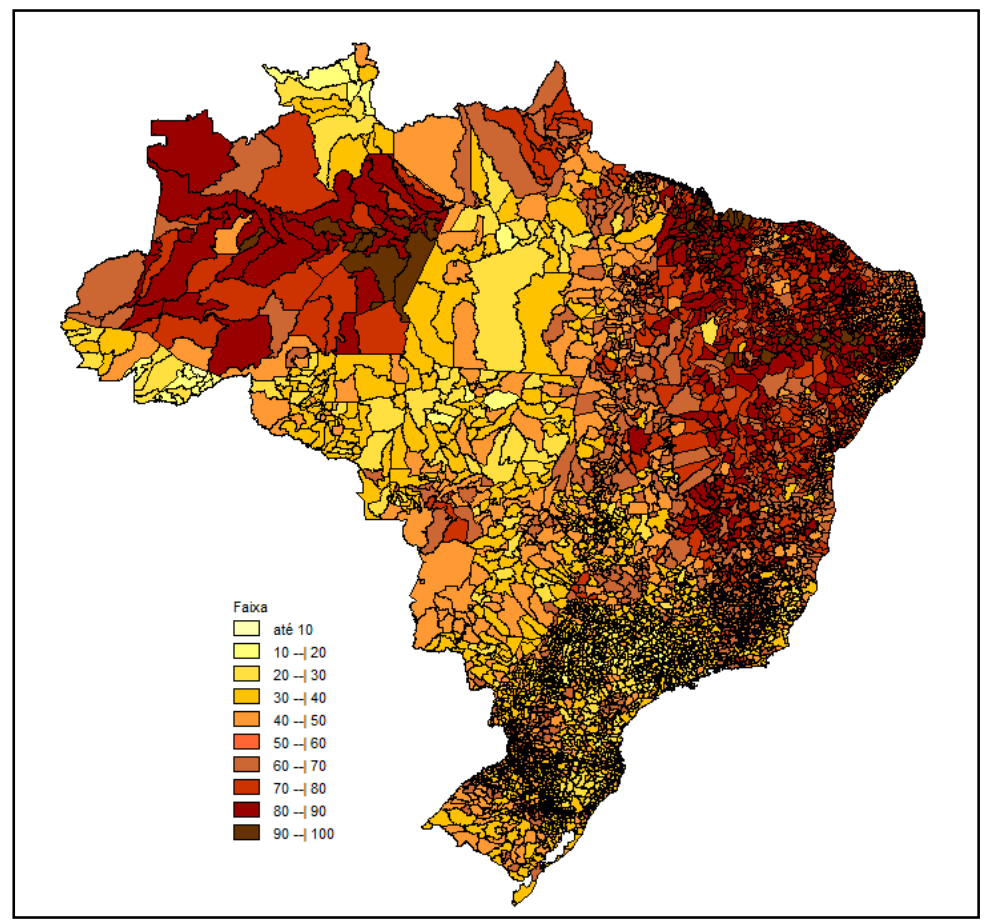

Fonte: Elaboração própria a partir de dados do TSE. 


\section{Figura 4 \\ Distribuição dos votos de Dilma no segundo turno de 2010 como proporção do total de votos válidos}

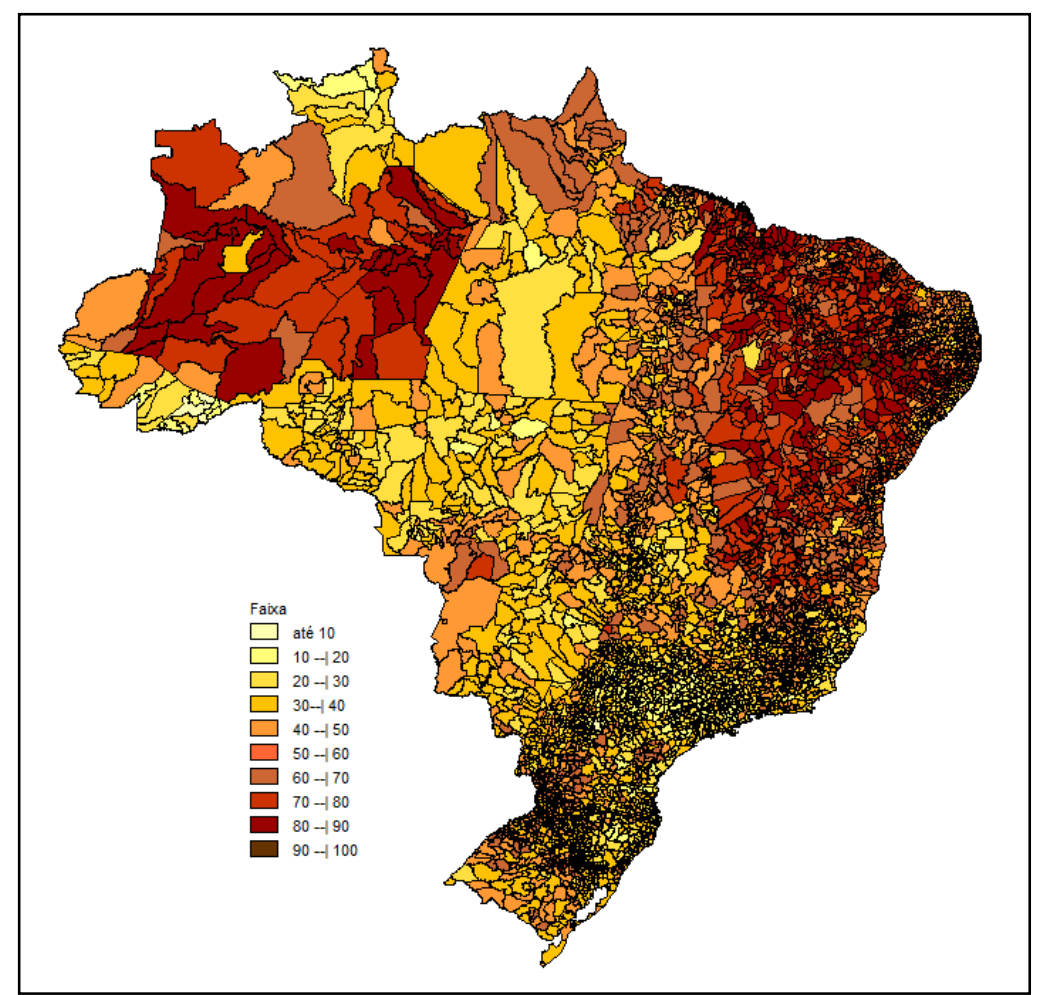

Fonte: Elaboração própria a partir de dados do TSE.

Embora esse autor considere parte das questões socioeconômicas e do programa Bolsa Família em sua análise, ele não considera a possibilidade de utilizar a votação de 2006 em Lula como parte explicativa dos votos de Dilma nos pleitos que se seguiram. Pensando na eleição de Dilma como um referendo à administração de Lula, é possível analisar os resultados de 2010 usando a mesma linha de análise adotada para os trabalhos acima citados para o pleito de 2006. Dessa forma, além de questionar qual foi o papel do Bolsa Família na eleição de Dilma, é importante entender qual a força de Lula nesse processo. A próxima seção apresenta a estratégia empírica e os dados utilizados neste artigo.

Antes de discutir os dados e a estratégia empírica, vale notar que a discussão sobre os efeitos de programas governamentais nos resultados de eleições não se restringe ao caso brasileiro. Por exemplo, Cerda e Vergara (2008), Manacorda, Miguel e Vigorito (2011), De La O (2013), Labonne (2013), dentre outros, investigam essa temática em outros contextos nacionais. Cerda e Vergara (2008) investigam os efeitos de 
subsídios governamentais nas eleições presidenciais do Chile no período de 1989-1999 e mostram que quanto maior a cobertura desses programas, medida pelo percentual de pessoas que são beneficiárias, maiores são os votos recebidos pelo candidato incumbente. Similarmente, Manacorda, Miguel e Vigorito (2011) analisam os efeitos do programa Panes no Uruguai e mostram evidência de que os efeitos são positivos e persistem mesmo após a finalização do programa de transferência de renda. De La $O$ (2013) investiga os efeitos do Progresa no México, o equivalente ao Bolsa Família brasileiro. Um dos resultados mais interessantes é a indicação de programas de transferência de renda ajudam na mobilização dos eleitores partidários do partido incumbente, o que, segundo De La O (2013), explica por que tais programas recebem suporte de candidatos de todas as vertentes político-partidárias. Finalmente, Labonne (2013) investiga os efeitos de programas nacionais sobre eleições locais nas Filipinas e mostra que, em localidades com ambiente político mais competitivo, os efeitos de tais programas são positivos sobre o desempenho eleitoral dos incumbentes, enquanto em locais de baixa competição os efeitos são nulos. Em resumo, a temática sobre os efeitos de programas sociais nos resultados eleitorais tem sido objeto de estudo em diferentes contextos.

\section{Estratégia empírica}

\section{Modelo de regressão}

A estratégia empírica é relativamente simples. São consideradas como variáveis dependentes os desempenhos eleitorais de Dilma em 2010 nos dois turnos e o de Marina no primeiro. Nós estamos particularmente interessados nos resultados do primeiro turno, na medida em que os números de segundo turno incluem ruídos como votos úteis e não representam necessariamente os efeitos das variáveis políticas e econômicas que buscamos identificar na análise. Todavia, os resultados de Dilma são apresentados para os dois turnos.

As variáveis explicativas podem ser divididas em quatro grupos, a saber: efeito do Bolsa Família; força de Lula; características municipais (partido dos prefeitos, PIB, concentração de renda, proporção de pobres na população, nível de educação, tamanho, grau de urbanização e localização); e religião. Essa última variável foi incluída para buscar identificar alguma relação com a votação de Marina Silva em 2010 e suas possíveis implicações para a eleição de 2014.

Mais formalmente o modelo de regressão que representa os relacionamentos das variáveis pode ser descrito da seguinte forma:

$$
Y_{i s}=X^{\prime} \beta+u_{s}
$$


Onde $Y_{\text {is }}$ é a proporção de votos do candidato $\mathrm{i}=\{$ Dilma ou Marina $\}$, no primeiro ou segundo turnos das eleições de 2010 no município s, X é uma matriz que contém os determinantes das votações, $\beta$ é um vetor de coeficientes associados com as diferentes características contidas na matriz $X$, e $U_{s}$ representa um vetor de erros dos modelos de regressão.

Num primeiro momento serão estimadas diferentes versões do modelo (1) acima, todas por mínimos quadrados ordinários com correção para heterocedasticidade, mas sem correção de erro espacial. Isso é feito numa segunda etapa, conforme descrito a seguir.

De forma a verificar a robustez dos resultados, as variáveis explicativas são incluídas de forma gradual. O modelo inicial inclui apenas o Bolsa Família. Em seguida são incluídas as participações de Lula na eleição de 2006 no primeiro turno, além da variável que representa o programa. Na sequência são incluídas as variáveis de características municipais e de religião. Todos os modelos incluem dummies estaduais (São Paulo é omitido para evitar multicolinearidade perfeita) para tentar controlar por características específicas dos estados não capturadas pelas demais variáveis. Os resultados serão apresentados na seção "Resultados das estimações".

\section{Modelo de regressão com correção espacial}

A autocorrelação ou dependência espacial pode afetar o termo de erro, a variável dependente ou ambos. A não consideração desse efeito pode gerar problemas de estimação, uma vez que, na presença de autocorrelação espacial nos resíduos, os parâmetros estimados por (1) são ineficientes. Da mesma forma, a dependência espacial na proporção de votos de um município em relação à votação dos municípios vizinhos provocará estimações tendenciosas e inconsistentes para os parâmetros, em virtude de um erro de especificação no modelo, pela não inclusão de uma variável dependente espacialmente defasada no modelo (1). Nos dois casos, a estimação por MQO mostra-se inadequada, devendo ser substituída por modelos espaciais. Os modelos de erro e defasagem espacial são apresentados a seguir.

\section{Modelo de dependência no erro}

Nessa estrutura o termo de erro segue um processo espacial autorregressivo da seguinte forma:

$$
\varepsilon_{t}=\lambda \mathbf{W} \varepsilon_{t}+u_{t}
$$

onde $\lambda$ é um escalar que representa o coeficiente da correlação espacial do erro, $\mathrm{W}$ é uma matriz de pesos espaciais e $u_{t}$ é normalmente distribuído com média zero e desviopadrão constante. 
Essa matriz, normalmente conhecida como W, pode ser usada para capturar padrões de adjacência das unidades geográficas. No caso mais simples, uma matriz simétrica é definida como tendo o elemento $(i, j)$ igual a 1 se $i$ e $j$ são vizinhos e 0 no caso contrário. Por convenção, os elementos diagonais são iguais a zero, $w_{i i}=0$. A matriz de peso espacial pode ser padronizada pela linha, denominada pelo sobrescrito $s$, com cada um dos seus elementos que têm valor diferente de zero sendo definido por $w_{i j}^{s}=w_{i j} / \sum_{j} w_{i j}$. Nesta matriz, os elementos das linhas somam 1. Além de facilitar a interpretação dos pesos (que variam entre 0 e 1 ) como uma média dos valores dos vizinhos, essa manipulação assegura a comparabilidade entre modelos (Anselin e Bera, 1998). Há ainda outras especificações mais complexas de matrizes de peso baseadas, por exemplo, em variáveis econômicas (ver Cliff e Ord, 1973, 1981, e Case, Rosen e Hines, 1993). Marzagão (2013) testa uma matriz de contiguidade versus uma cujos pesos são dados pelo inverso da distância e encontra resultados semelhantes em ambos os casos. Aqui será adotada a matriz de contiguidade pela sua simplicidade de uso e porque matrizes mais complexas não tendem a agregar informação no presente caso.

A equação a ser estimada teria a seguinte forma geral:

$$
Y=X \beta+(I-\lambda W)^{-1} u
$$

Para obter estimativas eficientes dos parâmetros das equações (3), faz-se necessário utilizar o estimador baseado na função de verossimilhança (ver Anselin, 1988).

$$
L=\frac{n}{2} \ln (\pi)-\frac{n}{2} \ln \left(\sigma^{2}\right)+\ln |\mathbf{I}-\lambda \mathbf{W}|-\frac{1}{2 \sigma^{2}} \varepsilon^{\prime}(\mathbf{I}-\lambda \mathbf{W})^{\prime}(\mathbf{I}-\lambda \mathbf{W}) \varepsilon
$$

O modelo final com correção espacial é então considerado. Mais uma vez, por limitações de espaço, apenas os modelos espaciais são apresentados para Marina e para o segundo turno de Dilma (as regressões sem correção espacial são incluídas nos Anexos).

\section{O modelo de defasagem espacial}

O efeito de defasagem espacial é ocasionado pela dependência espacial criada através de uma interação espacial entre os municípios, uma espécie de "efeito de vizinhança" na determinação da variável dependente. Nesse caso, essa influência é medida pela inclusão de uma variável adicional no modelo, dada por $W Y$, que é a variável dependente espacialmente defasada. Cada elemento $w y_{i}$, do vetor $W Y$, é formado por uma ponderação dos votos dos municípios vizinhos. Com a incorporação dessa variável, o modelo estimado passa a ser

$$
Y=X \beta+\rho W Y+\varepsilon
$$


onde $\rho$ é o coeficiente de autocorrelação espacial da variável $W Y$ e $\varepsilon$ é idêntica e independentemente distribuído (i.i.d.).

Da mesma forma que no modelo (3), a estimação deve ser realizada pelo método da máxima verossimilhança, que consiste na maximização da função $(6)^{7}$, utilizando técnicas de otimização não linear.

$$
L=\frac{n}{2} \ln (\pi)-\frac{n}{2} \ln \left(\sigma^{2}\right)+\ln |\mathbf{I}-\rho \mathbf{W}|-\frac{1}{2 \sigma^{2}} \varepsilon^{\prime} \varepsilon
$$

Os principais testes utilizados para detectar a autocorrelação espacial são: Moran I (erro); LM Robusto (erro) e LM Robusto (defasagem). O teste de Moran I, apesar de ser um teste robusto à forma de autocorrelação espacial, indica a presença ou não de autocorrelação espacial, mas não indica se o tipo de efeito é de erro ou de defasagem espacial, fator importante para a escolha do modelo. Por isso, neste artigo, são utilizados também outros testes, mais específicos: o LM (erro) Robusto para detectar efeitos de autocorrelação espacial no termo de erro; e o LM (defasagem) Robusto para verificar a presença de efeitos de defasagem espacial na variável dependente. Maiores detalhes podem ser encontrados em Anselin (1988). O teste LM (erro) Robusto é um teste assintótico realizado a partir da estatística

$$
L M_{\lambda}=\left[\left(\varepsilon^{\prime} W \varepsilon\right) / \sigma^{2}\right]^{2} / \operatorname{tr}\left[\left(W^{\prime}+W\right) W\right]
$$

onde $\varepsilon$ é o vetor de resíduos de mínimos quadrados; $W$, a matriz de pesos espaciais; $\sigma^{2}$ é estimativa de máxima verossimilhança da variância do modelo de mínimos quadrados; $n$, o número de dados da amostra e $t r$, o operador denominado traço da matriz, que tem distribuição qui-quadrado com um grau de liberdade, sob a hipótese nula de não existência de autocorrelação espacial no termo erro. O teste LM (defasagem) Robusto é também um teste assintótico realizado a partir da estatística

$$
L M_{\rho}=\tilde{d}_{\rho}^{2} / \widetilde{T}_{1}=\left[\left(\varepsilon^{\prime} W y\right) / \tilde{\sigma}^{2}\right]^{2} / \widetilde{T}_{1}
$$

onde $T_{1}=\left[(W X \beta)^{\prime} M(W X \beta)+T \sigma^{2}\right] / \sigma^{2}, T=\operatorname{tr}\left[\left(W^{\prime}+W\right) W\right]$ e $M=I-X\left(X^{\prime} X\right) X$.

Esse teste tem distribuição qui-quadrado com um grau de liberdade, sob a hipótese nula de não existência de defasagem espacial na variável dependente.

Uma boa resenha sobre a outra metodologia pode ser encontrada em Guervós (1999). A seguir apresentamos brevemente os dados utilizados nas estimações dos modelos.

\footnotetext{
${ }^{7}$ Uma derivação de estimador de verossimilhança pode ser encontrada em Anselin (1988).
} 
Os dados

A Tabela 1 apresenta uma breve descrição das variáveis dependentes e independentes utilizadas e de suas fontes ${ }^{8}$. Os dados das tabelas seguintes também têm como base essas fontes:

Tabela 1

Definição das variáveis utilizadas

\begin{tabular}{|c|c|c|}
\hline Variáveis & Definição & Fonte \\
\hline dilma_10_1 & $\begin{array}{l}\text { Percentual de votos de Dilma sobre votos } \\
\text { válidos no } 1^{\circ} \text { turno da eleição de } 2010\end{array}$ & Tribunal Superior Eleitoral (TSE) \\
\hline dilma_10_2 & $\begin{array}{l}\text { Percentual de votos de Dilma sobre votos } \\
\text { válidos no } 2^{\circ} \text { turno da eleição de } 2010\end{array}$ & Tribunal Superior Eleitoral (TSE) \\
\hline serra_10_1 & $\begin{array}{l}\text { Percentual de votos de Serra sobre votos } \\
\text { válidos no } 1^{\circ} \text { turno da eleição de } 2010\end{array}$ & Tribunal Superior Eleitoral (TSE) \\
\hline marina_10 & $\begin{array}{l}\text { Percentual de votos de Marina sobre votos } \\
\text { válidos no } 1^{\circ} \text { turno da eleição de } 2010\end{array}$ & Tribunal Superior Eleitoral (TSE) \\
\hline lula_06_1 & $\begin{array}{l}\text { Percentual de votos de Lula sobre votos } \\
\text { válidos no } 1^{\circ} \text { turno da eleição de } 2006\end{array}$ & Tribunal Superior Eleitoral (TSE) \\
\hline BF_sh_10 & $\begin{array}{l}\text { Percentual de pessoas beneficiadas pelo } \\
\text { Bolsa Família no município }\end{array}$ & $\begin{array}{l}\text { Ministério do Desenvolvimento } \\
\text { Social (MDS) }\end{array}$ \\
\hline Pobres_share & $\begin{array}{l}\text { Percentual de pessoas extremamente } \\
\text { pobres em } 2010 \text {. O cálculo considerou o } \\
\text { número de residentes em domicílios cuja } \\
\text { renda domiciliar per capita era igual ou } \\
\text { inferior a } \mathrm{R} \$ 70,00 \text { em } 2010 \text {. }\end{array}$ & $\begin{array}{l}\text { Elaborada pelos autores a partir } \\
\text { dos dados do IBGE, Censo } \\
\text { Demográfico-2010. }\end{array}$ \\
\hline pref_pt & Dummy para prefeitura do PT em 2008 & $\begin{array}{l}\text { Criada a partir dos dados do } \\
\text { Tribunal Superior Eleitoral (TSE) }\end{array}$ \\
\hline pref_pmdb & Dummy para prefeitura do PMDB em 2008 & $\begin{array}{l}\text { Criada a partir dos dados do } \\
\text { Tribunal Superior Eleitoral (TSE) }\end{array}$ \\
\hline pref_psdb & Dummy para prefeitura do PSBD em 2008 & $\begin{array}{l}\text { Criada a partir dos dados do } \\
\text { Tribunal Superior Eleitoral (TSE) }\end{array}$ \\
\hline Inpibpc10 & Log do PIB per capita municipal em 2010 & $\begin{array}{l}\text { Instituto Brasileiro de Geografia e } \\
\text { Estatística (IBGE) }\end{array}$ \\
\hline Inpop10 & Log da população municipal em 2010 & $\begin{array}{l}\text { Instituto Brasileiro de Geografia e } \\
\text { Estatística (IBGE) }\end{array}$ \\
\hline Dens_2010 & $\begin{array}{l}\text { Densidade populacional por município em } \\
2010\end{array}$ & $\begin{array}{l}\text { Instituto Brasileiro de Geografia e } \\
\text { Estatística (IBGE) }\end{array}$ \\
\hline tx_urb & $\begin{array}{lccc}\begin{array}{l}\text { Percentual da população } \\
\text { município em } 2010\end{array} & & \\
\end{array}$ & $\begin{array}{l}\text { Instituto Brasileiro de Geografia e } \\
\text { Estatística (IBGE) }\end{array}$ \\
\hline Gini_10 & Coeficiente de Gini municipal em 2010 & $\begin{array}{l}\text { Instituto Brasileiro de Geografia e } \\
\text { Estatística (IBGE) }\end{array}$ \\
\hline Analf_10 & $\begin{array}{l}\text { Percentual da população com } 25 \text { anos ou } \\
\text { mais analfabeta por município }\end{array}$ & $\begin{array}{l}\text { Instituto Brasileiro de Geografia e } \\
\text { Estatística (IBGE) }\end{array}$ \\
\hline tx_mort_10 & $\begin{array}{l}\text { Taxa de mortalidade infantil por município } \\
\text { em } 2010\end{array}$ & $\begin{array}{l}\text { Instituto Brasileiro de Geografia e } \\
\text { Estatística (IBGE) }\end{array}$ \\
\hline
\end{tabular}

${ }^{8}$ As fontes desses dados são, basicamente, o Tribunal Superior Eleitoral (TSE), para as variáveis eleitorais, o Instituto Brasileiro de Geografia e Estatística (IBGE), para as variáveis geográficas, demográficas e socioeconômicas, e o Ministério do Desenvolvimento Social (MDS) para informações sobre a cobertura do programa Bolsa Família. 
ANDRÉ MATOS MAGALHÃES; MARCELO EDUARDO ALVES DA SILVA; FERNANDO DE MENDONÇA DIAS

\begin{tabular}{|l|l|l|}
\hline Variáveis & Definição & Fonte \\
\hline sh_evang & Percentual de evangélicos no município & $\begin{array}{l}\text { Instituto Brasileiro de Geografia e } \\
\text { Estatística (IBGE) }\end{array}$ \\
\hline sh_cato & Percentual de católicos no município & $\begin{array}{l}\text { Instituto Brasileiro de Geografia e } \\
\text { Estatística (IBGE) }\end{array}$ \\
\hline sh_semrel & $\begin{array}{l}\text { Percentual de pessoas sem religião no } \\
\text { município }\end{array}$ & $\begin{array}{l}\text { Instituto Brasileiro de Geografia e } \\
\text { Estatística (IBGE) }\end{array}$ \\
\hline
\end{tabular}

Fonte: Elaboração própria.

A Tabela 2 apresenta algumas estatísticas descritivas das variáveis utilizadas. Os números evidenciam as disparidades socioeconômicas e demográficas entre os municípios da amostra. Por exemplo, ao mesmo tempo em que há municípios no país nos quais as taxas de analfabetismo na população acima de 25 anos são inferiores a 1\%, há outros onde essa taxa chega a $40 \%$. Há diferenças significativas entre as taxas de mortalidade infantil, PIB per capita e concentração de renda.

Tabela 2

Sumário das variáveis utilizadas

\begin{tabular}{|l|c|c|c|c|}
\hline Variáveis & Média & Desvio-padrão & Mínimo & Máximo \\
\hline dilma_10_1 & 55,311 & 15,823 & 15,839 & 94,838 \\
\hline dilma_10_2 & 59,492 & 15,390 & 19,669 & 96,505 \\
\hline serra_10_1 & 33,598 & 14,059 & 2,505 & 75,053 \\
\hline marina_10 & 10,365 & 6,151 & 0,935 & 42,473 \\
\hline lula_06_1 & 51,622 & 17,852 & 11,409 & 93,367 \\
\hline BF_sh_10 & 9,460 & 4,951 & 0,000 & 23,831 \\
\hline pobres_share & 12,97 & 11,68 & 0,053 & 69,94 \\
\hline pref_pt & 0,100 & 0,300 & 0,000 & 1,000 \\
\hline pref_pmdb & 0,216 & 0,412 & 0,000 & 1,000 \\
\hline pref_psdb & 0,335 & 0,472 & 0,000 & 1,000 \\
\hline Inpibpc10 & 9,177 & 0,697 & 7,727 & 12,601 \\
\hline Inpop10 & 9,415 & 1,151 & 6,691 & 16,236 \\
\hline Dens_2010 & 108,783 & 573,343 & 0,131 & $13.165,880$ \\
\hline tx_urb & 63,826 & 22,041 & 4,179 & 100,000 \\
\hline Gini_10 & 0,494 & 0,066 & 0,280 & 0,800 \\
\hline Analf_10 & 14,741 & 8,936 & 0,900 & 41,600 \\
\hline tx_mort_10 & 14,260 & 14,282 & 0,000 & 333,333 \\
\hline sh_evang & 16,544 & 9,442 & 0,000 & 90,000 \\
\hline sh_cato & 75,969 & 13,454 & 10,000 & 100,000 \\
\hline sh_semrel & 5,138 & 4,820 & 0,000 & 51,696 \\
\hline
\end{tabular}

Fonte: Elaboração própria com base em dados do TSE, MDS e IBGE, conforme descrição na Tabela 1.

Notas: Os dados representam médias e proporções municipais. 
Antes de discutirmos os resultados dos modelos estimados, vale a pena destacar que uma questão importante na literatura é o viés de agregação. Idealmente, para investigar os determinantes do desempenho eleitoral de candidatos, usaríamos informações em nível individual, além de variáveis com maiores níveis de agregação, que poderiam influenciar decisões individuais e que, de certa forma, estão consideradas neste artigo (e.g. distribuição de renda, características regionais etc.). Infelizmente dados em nível individual não estão disponíveis e isso tem levado a maioria dos autores a utilizar dados agregados na análise de desempenhos eleitorais. Contudo, se os eleitores possuem características heterogêneas, é razoável supor que a inferência a partir de dados agregados possa apresentar problemas. Embora a questão do viés de agregação seja importante, neste artigo nos concentramos nos problemas quando a dimensão espacial é ignorada9.

A seguir apresentamos e discutimos os principais resultados deste artigo.

\section{Resultados das estimações}

As Tabelas de 3 a 8 apresentam os principais resultados. Inicialmente podem ser observados os resultados de Dilma no primeiro turno para o modelo sem correção espacial e, posteriormente, com a correção espacial. Na sequência são apresentados os resultados para Dilma no segundo turno (apenas no modelo com correção espacial) e, em seguida, apresentamos os resultados para a votação de Marina no primeiro turno. Por fim, os resultados de um exercício contrafactual são discutidos na tentativa de mensurar os efeitos da votação de Lula em 2006, o "efeito Lula", e da cobertura do Bolsa Família, o "efeito Bolsa", sobre o desempenho eleitoral de Dilma no primeiro turno de 2010.

\section{Resultados para a votação Dilma no primeiro turno de 2010}

A Tabela 3 apresenta três regressões para a votação de Dilma no primeiro turno de 2010. A primeira regressão inclui apenas a participação do Bolsa Família como variável explicativa, além de uma constante. Na segunda regressão, a votação de Lula no primeiro turno de 2006 é acrescentada. Por fim, o último modelo inclui os demais controles.

A análise da Tabela 3 informa que o Bolsa Família tem uma correlação alta com a votação de Dilma. Todavia, a inclusão da votação de Lula em 2006 reduz aproximadamente pela metade o valor do coeficiente estimado para o programa. $\mathrm{Na}$ medida em que o Bolsa Família está relacionado com características municipais a última

\footnotetext{
${ }^{9}$ No contexto de modelos sem correção espacial, Canêdo-Pinheiro (2009) implementa um método proposto por Stoker (1993) na tentativa de minimizar o problema do viés de agregação. Zucco (2013) usa dados agregados e dados individuais para aumentar o grau de confiança nos seus resultados. Nós agradecemos um dos revisores anônimos por ter apontado esta questão.
} 
equação considera as demais variáveis socioeconômicas listadas acima como controles. As dummies para as unidades da Federação buscam capturar características específicas dos estados, não capturadas pelas demais variáveis (por facilidade de exposição, os resultados dos coeficientes estimados para os estados são apresentados na Tabela A3 dos Anexos). Pode-se observar (regressão 3) que, mesmo após a inclusão dos controles, os efeitos do Bolsa Família (BF) e da votação de Lula permanecem positivos e significativos. No entanto, uma mudança observada é que, no modelo final, o efeito Lula é maior do que o efeito do BF. Enquanto no modelo estimado sem demais controles (regressão 2), para cada aumento de $1 \%$ na cobertura do programa, o aumento no desempenho eleitoral de Dilma teria sido de 0,99 ponto percentual o efeito de um mesmo aumento na votação obtida por Lula em 2006 teria sido de 0,64 ponto percentual. No modelo com demais controles, o resultado é invertido. Enquanto o impacto de um aumento na cobertura do programa sobre a votação de Dilma teria sido de 0,356 ponto percentual, o "efeito Lula" teria acrescentado 0,661 ponto percentual.

Alguns outros resultados são dignos de nota. Como observado por outros autores para outros contextos, o desempenho de Dilma foi pior nos municípios governados pelo PT. Canêdo-Pinheiro (2009) e Zucco (2008) obtiveram resultados similares no contexto das eleições presidenciais de 2006 para o ex-presidente Lula. Um dos argumentos para o impacto negativo de prefeitos do PT é que este sinal refletiria o "abandono" dos eleitores habituais do PT nas eleições presidenciais daquele ano. O interessante é que esse comportamento se repete nas eleições de 2010, mas agora não mais com o expresidente Lula como candidato. Outro ponto digno de nota é que Dilma se saiu melhor nos municípios com menor taxa de urbanização, de menor porte populacional, com melhor distribuição de renda e com população de menor escolaridade. Por fim, embora o efeito seja pequeno, municípios com maior proporção de católicos também afetaram positivamente os resultados eleitorais de Dilma.

Tabela 3

Resultados das regressões para a votação de Dilma no primeiro turno de $\mathbf{2 0 1 0}$

\begin{tabular}{|l|c|c|c|}
\hline & $\mathbf{( 1 )}$ & $\mathbf{( 2 )}$ & $\mathbf{( 3 )}$ \\
& dilma_10_1 & dilma_10_1 & dilma_10_1 \\
\hline BF_sh_10 & $1,879 * * *$ & $0,990 * * *$ & $0,356 * *$ \\
& $(36,12)$ & $(23,91)$ & $(7,34)$ \\
\hline lula_06_1 & & $0,640 * * *$ & $0,661 * * *$ \\
& & $(62,39)$ & $(69,35)$ \\
\hline & & & $-2,719 * * *$ \\
pref_pt & & & $(-9,39)$ \\
\hline & & & $-0,288$ \\
& & & $(-1,27)$ \\
\hline \hline
\end{tabular}




\begin{tabular}{|c|c|c|c|}
\hline & $\begin{array}{c}(1) \\
\text { dilma_10_1 }\end{array}$ & $\begin{array}{c}(2) \\
\text { dilma_10_1 }\end{array}$ & $\begin{array}{c}\text { (3) } \\
\text { dilma_10_1 }\end{array}$ \\
\hline pref_psdb & & & $\begin{array}{l}-0,113 \\
(-0,55)\end{array}$ \\
\hline Inpibpc10 & & & $\begin{array}{c}0,217 \\
(1,02) \\
\end{array}$ \\
\hline Inpop10 & & & $\begin{array}{c}-0,536 * * * \\
(-5,28)\end{array}$ \\
\hline Dens_2010 & & & $\begin{array}{c}0,000206 \\
(1,44)\end{array}$ \\
\hline tx_urb & & & $\begin{array}{c}-0,0710 * * * \\
(-11,98)\end{array}$ \\
\hline Gini_10 & & & $\begin{array}{c}-7,540 * * * \\
(-4,15)\end{array}$ \\
\hline Analf_10 & & & $\begin{array}{c}0,0821 * * * \\
(3,01)\end{array}$ \\
\hline tx_mort_10 & & & $\begin{array}{c}0,00297 \\
(0,45)\end{array}$ \\
\hline pobres_share & & & $\begin{array}{c}0,157 * * * \\
(8,74) \\
\end{array}$ \\
\hline sh_evang & & & $\begin{array}{c}-0,0312 \\
(-1,57)\end{array}$ \\
\hline sh_cato & & & $\begin{array}{c}0,0393 * * \\
(2,07)\end{array}$ \\
\hline sh_semrel & & & $\begin{array}{c}-0,201 * * * \\
(-5,74)\end{array}$ \\
\hline Constante & $\begin{array}{c}30,26 * * * \\
(74,78) \\
\end{array}$ & $\begin{array}{c}11,78 * * * \\
(30,67) \\
\end{array}$ & $\begin{array}{c}24,48 * * * \\
(8,04) \\
\end{array}$ \\
\hline Observações & 5565 & 5565 & 5555 \\
\hline R-quadrado & 0,672 & 0,821 & 0,856 \\
\hline $\begin{array}{l}\text { R-quadrado } \\
\text { Ajustado }\end{array}$ & 0,670 & 0,820 & 0,855 \\
\hline
\end{tabular}

Fonte: Elaboração própria.

Estatísticas t entre parênteses. Significância: * $p<0,10, * * p<0,05, * * * p<0,01$.

Nota: as dummies estaduais foram omitidas por economia de espaço, mas são apresentadas na Tabela A3 dos Anexos. Todos os modelos foram estimados por mínimos quadrados ordinários com correção para heterocedasticidade. As variáveis foram checadas para multicolinearidade. Os resultados são apresentados nos Anexos.

A Tabela 4 apresenta o teste de correlação espacial para o modelo 3 . Os resultados indicam a presença de correlação espacial tanto no erro quanto no componente autorregressivo, entretanto, os valores para o erro são superiores aos do 
segundo caso. Nessas situações, com indicação dos dois tipos de dependência espacial pelos testes de Multiplicador de Lagrange, a literatura indica uma regra simples: estimase o modelo de regressão definido pelo maior valor do teste robusto. No presente caso, o valor do teste para o modelo de erro é estatisticamente significante e superior ao do modelo de defasagem ${ }^{10}$.

Dessa forma, a Tabela 5 apresenta os resultados para o modelo $3 \mathrm{com}$ a correção espacial para o erro ${ }^{11}$.

Tabela 4

Teste de dependência espacial para regressão (3) da Tabela 3

\begin{tabular}{|l|c|c|c|}
\hline Testes & MI/DF & Valores & Probabilidade \\
\hline I de Moran (erro) & 0,3586 & 44,5516 & 0,0000 \\
\hline $\begin{array}{l}\text { Multiplicador de Lagrange } \\
\text { (defasagem) }\end{array}$ & 1,0000 & 1169,9627 & 0,0000 \\
\hline $\begin{array}{l}\text { Multiplicador de Lagrange Robusto } \\
\text { (defasagem) }\end{array}$ & 1,0000 & 68,5131 & 0,0000 \\
\hline Multiplicador de Lagrange (erro) & 1,0000 & 1894,4077 & 0,0000 \\
\hline $\begin{array}{l}\text { Multiplicador de Lagrange Robusto } \\
\text { (erro) }\end{array}$ & 1,0000 & 792,9581 & 0,0000 \\
\hline Multiplicador de Lagrange (Sarma) & 2,0000 & 1962,9208 & 0,0000 \\
\hline
\end{tabular}

Fonte: Elaboração própria.

Os resultados da estimação do modelo com correção espacial (Tabela 5) confirmam aqueles encontrados no modelo sem correção espacial (Tabela 3). Ambos os efeitos (Lula e Bolsa Família) continuam positivos e significantes com o efeito "Lula" permanecendo com maior impacto marginal quando comparado ao efeito "Bolsa Família". Para cada aumento de $1 \%$ na cobertura do programa, o aumento na votação de Dilma teria sido de aproximadamente 0,40 ponto percentual. Enquanto para um mesmo aumento de $1 \%$ na votação de Lula em 2006, o efeito sobre o desempenho eleitoral de Dilma teria sido de 0,62 ponto percentual. Nota-se ainda que a votação de Dilma tendeu a ser maior em municípios menores, rurais, com melhor distribuição de renda e com maior participação de analfabetos ${ }^{12}$. O efeito do PT permanece negativo. Ademais, quanto maior a proporção de católicos, melhor o desempenho eleitoral de Dilma. O

\footnotetext{
${ }^{10}$ Outro ponto importante para verificar a robustez do modelo estimado é testar mais de um tipo de matriz de distância (ver, por exemplo, Guervós, 1999). Os resultados a seguir foram obtidos com uma matriz de distância simples (critério de vizinhança rook), mas um modelo com uma matriz com o inverso da distância também foi estimado e apresentou resultados semelhantes.

${ }^{11} \mathrm{O}$ trabalho de Marzagão (2013) também aponta para a dependência espacial no erro. A razão para tal seria a omissão de variável que capturasse a dimensão espacial das campanhas. Tal ausência conduziria a erros espacialmente correlacionados.

${ }^{12}$ Esse resultado é encontrado em outros trabalhos que consideram a eleição de Lula em 2006. Ver, por exemplo, Zucco (2008).
} 
inverso é verdadeiro para a proporção dos que se declaram sem religião na população:

Tabela 5

Resultado do modelo de erro espacial para proporção de votos em Dilma no primeiro turno de 2010

\begin{tabular}{|l|c|c|c|c|}
\hline Variáveis & Coeficientes & $\begin{array}{c}\text { Desvio- } \\
\text { padrão }\end{array}$ & Valor z & Probabilidade \\
\hline Constante & 18,6653 & 2,0722 & 9,0073 & 0,0000 \\
\hline BF_sh_10 & 0,4091 & 0,0446 & 9,1766 & 0,0000 \\
\hline Pobres_share & 0,1261 & 0,0162 & 7,7909 & 0,0000 \\
\hline lula_06_1 & 0,6233 & 0,0091 & 68,6785 & 0,0000 \\
\hline pref_pt & $-2,4805$ & 0,2458 & $-10,0916$ & 0,0000 \\
\hline pref_pmdb & $-0,2537$ & 0,1872 & $-1,3551$ & 0,1754 \\
\hline pref_psdb & $-0,1104$ & 0,1683 & $-0,6558$ & 0,5120 \\
\hline Inpibpc10 & $-0,0776$ & 0,1684 & $-0,4607$ & 0,6450 \\
\hline Inpop10 & $-0,7567$ & 0,0876 & $-8,6376$ & 0,0000 \\
\hline Dens_2010 & 0,0000 & 0,0000 & 0,0814 & 0,9351 \\
\hline tx_urb & 0,0000 & 0,0000 & $-3,6855$ & 0,0002 \\
\hline Gini_10 & $-5,3912$ & 1,6161 & $-3,3360$ & 0,0009 \\
\hline Analf_10 & 0,1656 & 0,0277 & 5,9693 & 0,0000 \\
\hline tx_mort_10 & $-0,0015$ & 0,0048 & $-0,3036$ & 0,7615 \\
\hline sh_evang & 0,0198 & 0,0156 & 1,2684 & 0,2047 \\
\hline sh_cato & 0,0835 & 0,0146 & 5,7224 & 0,0000 \\
\hline sh_semrel & $-0,0595$ & 0,0286 & $-2,0854$ & 0,0370 \\
\hline Lambda & 0,6128 & 0,0139 & 44,0366 & 0,0000 \\
\hline $\begin{array}{l}\text { R-quadrado } \\
\text { Verossimilhança } \\
\text { Critério de informação de Akaike } \\
\text { Critério de Schwarz }\end{array}$ & $\begin{array}{l}34604,2 \\
34889,0\end{array}$ & & \\
\hline
\end{tabular}

Fonte: Elaboração própria.

Nota: Estimado por máximo de verossimilhança. Estimado com dummies estaduais.

Resultados para a votação de Dilma no segundo turno de 2010

A mesma análise é repetida para a votação em Dilma no segundo turno de 2010. Nesse caso uma variável adicional é incluída para tentar captar a transferência de votos de Marina. Os resultados encontrados são semelhantes aos apresentados na análise do primeiro turno. No modelo de regressão sem correção espacial (Tabela A1 dos Anexos), os efeitos do Bolsa Família e da votação de Lula em 2006 continuam positivos, e o 
coeficiente associado ao "efeito Lula" é superior ao coeficiente que captura o "efeito Bolsa Família". No modelo de regressão com correção espacial (Tabela 6), para cada aumento de $1 \%$ na cobertura do programa, o aumento no desempenho eleitoral de Dilma teria sido de 0,26 ponto percentual, enquanto um mesmo aumento na votação obtida por Lula em 2006, mas agora no segundo turno, teria tido um impacto positivo de 0,74 ponto percentual.

Um resultado interessante é que o efeito de Marina sobre a votação de Dilma é negativo e significante, ou seja, Dilma teve uma votação menor no segundo turno nos municípios em que Marina teve maior participação no primeiro turno. Apesar de ser uma análise agregada, pode-se argumentar que o eleitor de Marina não estava disposto a votar em Dilma.

Os efeitos das demais variáveis são semelhantes. Por exemplo, o fato de a prefeitura ser governada por um prefeito do PT continua tendo efeito negativo e de magnitude semelhante ao observado na votação do primeiro turno (Tabela 5). O mesmo pode ser observado para a proporção de analfabetos, urbanização e tamanho populacional.

Tabela 6

Resultado do modelo de erro espacial para proporção de votos em Dilma no segundo turno de 2010

\begin{tabular}{|l|c|c|c|c|}
\hline Variáveis & Coeficientes & Desvio-padrão & Valor $\mathbf{z}$ & Probabilidade \\
\hline Constante & 14,7458 & 1,8985 & 7,7670 & 0,0000 \\
\hline BF_sh_10 & 0,2621 & 0,0407 & 6,4326 & 0,0000 \\
\hline Pobres_share & 0,0983 & 0,0147 & 6,6749 & 0,0000 \\
\hline lula_06_2 & 0,7421 & 0,0086 & 86,7178 & 0,0000 \\
\hline pref_pt & $-2,4897$ & 0,2248 & $-11,0768$ & 0,0000 \\
\hline pref_pmdb & $-0,1536$ & 0,1712 & $-0,8973$ & 0,3696 \\
\hline pref_psdb & 0,0291 & 0,1540 & 0,1891 & 0,8500 \\
\hline Inpibpc10 & 0,2107 & 0,1546 & 1,3634 & 0,1728 \\
\hline Inpop10 & $-0,0788$ & 0,0839 & $-0,9386$ & 0,3480 \\
\hline Dens_2010 & $-0,0000$ & 0,0000 & $-0,2390$ & 0,8111 \\
\hline tx_urb & $-0,0000$ & 0,0000 & $-3,8797$ & 0,0001 \\
\hline Gini_10 & $-2,7602$ & 1,4767 & $-1,8692$ & 0,0616 \\
\hline Analf_10 & $-0,0761$ & 0,0257 & $-2,9622$ & 0,0031 \\
\hline tx_mort_10 & $-0,0028$ & 0,0044 & $-0,6437$ & 0,5198 \\
\hline sh_evang & 0,0214 & 0,0143 & 1,4976 & 0,1343 \\
\hline sh_cato & 0,0138 & 0,0134 & 1,0286 & 0,3037 \\
\hline sh_semrel & $-0,0508$ & 0,0261 & $-1,9510$ & 0,0511 \\
\hline
\end{tabular}


ELEIÇÃO DE DILMA OU SEGUNDA REELEIÇÃO DE LULA?

\begin{tabular}{|l|c|c|c|c|}
\hline Variáveis & Coeficientes & Desvio-padrão & Valor z & Probabilidade \\
\hline marina_10 & $-0,3153$ & 0,0222 & $-14,1770$ & 0,0000 \\
\hline Lambda & 0,5877 & 0,0144 & 40,7672 & 0,0000 \\
\hline R-quadrado & 0,9070 \\
Verossimilhança & $-16726,23$ \\
Critério de informação de Akaike & 33540,50 \\
Critério de Schwarz & 33831,90 \\
\hline
\end{tabular}

Fonte: Elaboração própria.

Nota: estimado por máximo de verossimilhança. Estimado com dummies estaduais

\section{O perfil do eleitor de Marina}

A Tabela 7 apresenta os resultados para a votação em Marina em 2010. O texto apresenta apenas o modelo com correção de erro espacial (as estimativas de MQO e os testes de autocorrelação espacial são apresentados nos Anexos). Alguns resultados merecem destaque. Em primeiro lugar, o efeito do Bolsa Família sobre a votação de Marina é negativo. Cada aumento de um ponto percentual na cobertura do programa significaria uma redução de 0,21 ponto percentual no desempenho eleitoral de Marina. Em segundo lugar, nota-se aqui que o efeito Lula é positivo, mas significante apenas a $10 \%$. Os coeficientes estimados, para os dois efeitos, nos modelos sem correção espacial (Tabela A2 nos Anexos) e com correção espacial (Tabela 7) são relativamente consistentes, embora no primeiro (regressão 3 na Tabela A2) o efeito Lula seja mais do que o dobro do efeito observado no modelo com correção espacial.

Por fim, o perfil do eleitor de Marina difere do perfil do eleitor de Dilma em algumas dimensões importantes. Os coeficientes indicam que o voto em Marina esteve positivamente correlacionado com municípios mais ricos, de maior população, urbanos e adensados, com maior desigualdade, com menor proporção de pobres e menor taxa de analfabetismo. Religião também teve um papel na sua votação, sendo que seus votos foram positivamente correlacionados com os evangélicos e negativamente correlacionados com os católicos. Esse parece ser o perfil oposto ao de Dilma. 
Figura 5

Distribuição dos votos de Marina no primeiro turno de 2010 como proporção do total de votos válidos

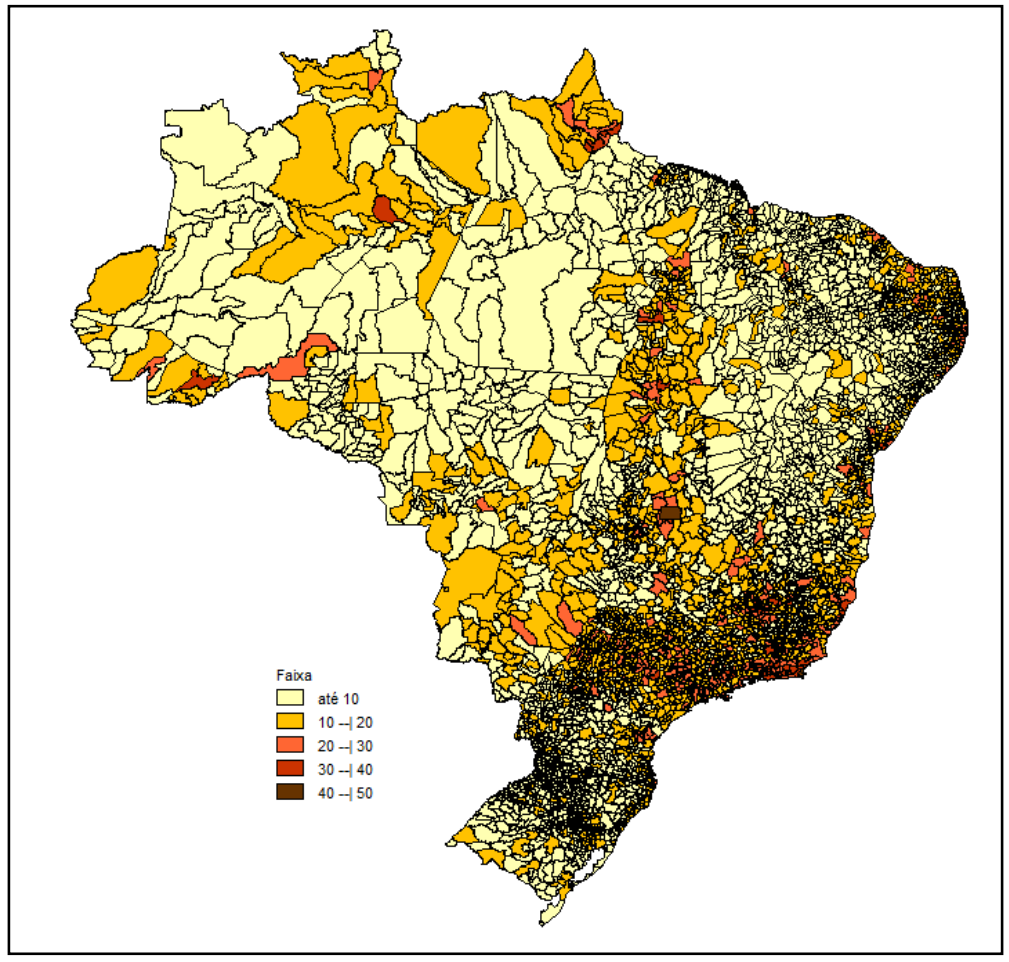

Fonte: Elaboração própria.

Tabela 7

Resultado do modelo de erro espacial para proporção de votos em Marina no primeiro turno de 2010

\begin{tabular}{|l|c|c|c|c|}
\hline Variáveis & Coeficientes & Desvio-padrão & Valor $\mathbf{z}$ & Probabilidade \\
\hline Constante & 1,8557 & 1,1145 & 1,6650 & 0,0959 \\
\hline BF_sh_10 & $-0,2069$ & 0,0243 & $-8,5159$ & 0,0000 \\
\hline Pobres_share & $-0,0250$ & 0,0088 & $-2,8441$ & 0,0045 \\
\hline lula_06_1 & 0,0100 & 0,0050 & 2,0182 & 0,0436 \\
\hline pref_pt & $-0,1460$ & 0,1316 & $-1,1095$ & 0,2672 \\
\hline pref_pmdb & 0,0087 & 0,1003 & 0,0865 & 0,9311 \\
\hline pref_psdb & $-0,2464$ & 0,0902 & $-2,7324$ & 0,0063 \\
\hline Inpibpc10 & 0,7878 & 0,0910 & 8,6583 & 0,0000 \\
\hline Inpop10 & 1,1608 & 0,0475 & 24,4260 & 0,0000 \\
\hline Dens_2010 & 0,0000 & 0,0000 & 1,7291 & 0,0838 \\
\hline
\end{tabular}


ELEIÇÃO DE DILMA OU SEGUNDA REELEIÇÃO DE LULA?

\begin{tabular}{|l|c|c|c|c|}
\hline Variáveis & Coeficientes & Desvio-padrão & Valor $\mathbf{z}$ & Probabilidade \\
\hline tx_urb & 0,0000 & 0,0000 & 3,6912 & 0,0002 \\
\hline Gini_10 & 2,4663 & 0,8714 & 2,8303 & 0,0047 \\
\hline Analf_10 & $-0,2364$ & 0,0153 & $-15,4075$ & 0,0000 \\
\hline tx_mort_10 & $-0,0007$ & 0,0026 & $-0,2905$ & 0,7714 \\
\hline sh_evang & 0,0154 & 0,0084 & 1,8287 & 0,0674 \\
\hline sh_cato & $-0,0661$ & 0,0078 & $-8,4157$ & 0,0000 \\
\hline sh_semrel & 0,0493 & 0,0155 & 3,1869 & 0,0014 \\
\hline Lambda & 0,6893 & 0,0123 & 56,2228 & 0,0000 \\
\hline R-quadrado & 0,7952 & \\
Verossimilhança \\
Critério de informação de Akaike \\
Critério de Schwarz
\end{tabular}

Fonte: Elaboração própria.

Nota: estimado por máximo verossimilhança. Estimado com dummies estaduais.

O "efeito Lula" versus o "efeito Bolsa Família"

Adicionalmente, implementamos um exercício que consiste em construir um contrafactual com o objetivo de avaliar os efeitos totais sobre o desempenho eleitoral de Dilma da cobertura do programa Bolsa Família e da votação de Lula em 2006, considerando os valores destas duas últimas em cada um dos municípios. É esperado que em municípios onde Lula tenha obtido uma votação alta em 2006, mas com baixa cobertura do programa, o apoio do ex-presidente tenha tido uma importância ainda maior sobre o desempenho eleitoral de Dilma em 2010. O mesmo princípio valeria para a importância do Bolsa Família em municípios com alta cobertura do programa, mas com menor votação de Lula em $2006^{13}$.

A Tabela 8 apresenta os resultados desse exercício contrafactual. Vale notar que embora todos os cálculos tenham sido realizados por município, por facilidade de exposição, apresentamos os resultados agregados por estado. A partir dos resultados das proporções obtidas para cada município, computamos o número de votos absolutos obtidos em cada municipalidade e agregamos os resultados em cada estado, o que nos dá uma estimativa agregada por estado (coluna B) comparável aos resultados efetivos obtidos por Dilma em cada uma das UFs brasileiras em 2010 (coluna A). Para ter uma ideia da importância conjunta dos dois efeitos, computamos para cada município qual teria sido a votação de Dilma caso tanto a votação de Lula quanto a cobertura do

\footnotetext{
${ }^{13}$ Agradecemos ao parecerista anônimo por ter sugerido esse exercício.
} 
programa fossem nulas (coluna $C)^{14}$. Depois acrescentamos apenas a votação de Lula, assumindo hipoteticamente que a cobertura do Bolsa Família fosse nula (coluna D). Por fim, assumimos a votação de Lula igual a zero e introduzimos a cobertura do programa (coluna E).

Denominamos de "efeito Lula" (coluna F) como o acréscimo, em pontos percentuais, que a introdução da votação do ex-presidente trouxe à votação de Dilma em 2010, relativamente ao caso em que nenhuma das duas variáveis (votação de Lula e cobertura do Bolsa Família) estão presentes. Similarmente, denominamos de "efeito Bolsa Família" como o acréscimo que a cobertura do programa trouxe à votação de Dilma, relativamente ao cenário em que nenhuma das duas variáveis estão presentes (coluna $G)^{15}$.

Tabela 8

Exercício Contrafactual

Votação de Dilma em 2010 - Efeito Lula versus Efeito Bolsa Família

\begin{tabular}{|c|c|c|c|c|c|c|c|}
\hline \multirow{2}{*}{ UF } & \multirow{2}{*}{$\begin{array}{c}\begin{array}{c}\text { Votação } \\
\text { de } \\
\text { Dilma } \\
\text { em } \\
2010\end{array} \\
\text { (A) }\end{array}$} & \multirow{2}{*}{$\begin{array}{c}\text { Votação } \\
\text { prevista } \\
\text { pelo } \\
\text { modelo } \\
\\
\text { (B) }\end{array}$} & \multirow{2}{*}{$\begin{array}{c}\text { Votação } \\
\text { prevista } \\
\text { com } \\
\text { controles } \\
\text { sem os } \\
\text { efeitos } \\
\\
\text { (C) }\end{array}$} & \multirow{2}{*}{$\begin{array}{c}\text { Votação } \\
\text { prevista } \\
\text { com } \\
\text { controles } \\
\text { e Lula } \\
\\
\text { (D) }\end{array}$} & \multirow{2}{*}{$\begin{array}{c}\text { Votação } \\
\text { prevista } \\
\text { com } \\
\text { controles } \\
\text { e Bolsa } \\
\text { Família } \\
\\
\text { (E) }\end{array}$} & \multicolumn{2}{|c|}{ Importância total } \\
\hline & & & & & & $\begin{array}{l}\text { Efeito Lula } \\
(F)=(D)- \\
\text { (C) }\end{array}$ & $\begin{array}{l}\text { Efeito Bolsa } \\
\text { Família (G) } \\
=(\mathrm{E})-(\mathrm{C})\end{array}$ \\
\hline \multicolumn{8}{|l|}{ Norte } \\
\hline RO & 40,74 & 41,00 & 9,76 & 38,01 & 12,75 & 28,25 & 3,00 \\
\hline$A C$ & 23,90 & 26,07 & $-3,78$ & 22,79 & $-0,50$ & 26,57 & 3,28 \\
\hline AM & 64,98 & 69,22 & 17,41 & 66,11 & 20,52 & 48,70 & 3,11 \\
\hline $\mathrm{RR}$ & 28,75 & 27,41 & 7,21 & 23,62 & 11,01 & 16,40 & 3,79 \\
\hline PA & 47,94 & 50,05 & 13,94 & 46,38 & 17,61 & 32,45 & 3,67 \\
\hline AP & 47,37 & 48,93 & 12,24 & 46,22 & 14,95 & 33,98 & 2,71 \\
\hline TO & 50,97 & 52,28 & 11,85 & 48,44 & 15,69 & 36,59 & 3,84 \\
\hline \multicolumn{8}{|c|}{ Nordeste } \\
\hline MA & 70,65 & 71,41 & 19,03 & 66,01 & 24,42 & 46,99 & 5,40 \\
\hline PI & 67,04 & 67,60 & 20,15 & 62,01 & 25,74 & 41,86 & 5,59 \\
\hline
\end{tabular}

${ }^{14}$ É importante notar que os resultados sem os dois efeitos presentes podem resultar em valores positivos ou negativos, é o que ocorre no estado do Acre, por exemplo.

${ }^{15}$ Para todos os cálculos utilizamos os coeficientes do modelo com correção espacial. Os cálculos foram feitos por município, mas foram agregados por estados para facilitar a análise. Os resultados completos estão disponíveis a partir de solicitação junto aos autores. 
ELEIÇÃO DE DILMA OU SEGUNDA REELEIÇÃO DE LULA?

\begin{tabular}{|c|c|c|c|c|c|c|c|}
\hline \multirow{2}{*}{ UF } & \multirow{2}{*}{$\begin{array}{c}\begin{array}{c}\text { Votação } \\
\text { de } \\
\text { Dilma } \\
\text { em } \\
2010\end{array} \\
\text { (A) }\end{array}$} & \multirow{2}{*}{$\begin{array}{c}\text { Votação } \\
\text { prevista } \\
\text { pelo } \\
\text { modelo }\end{array}$} & \multirow{2}{*}{$\begin{array}{c}\text { Votação } \\
\text { prevista } \\
\text { com } \\
\text { controles } \\
\text { sem os } \\
\text { efeitos } \\
\text { (C) }\end{array}$} & \multirow{2}{*}{$\begin{array}{c}\text { Votação } \\
\text { prevista } \\
\text { com } \\
\text { controles } \\
\text { e Lula } \\
\text { (D) }\end{array}$} & \multirow{2}{*}{$\begin{array}{c}\text { Votação } \\
\text { prevista } \\
\text { com } \\
\text { controles } \\
\text { e Bolsa } \\
\text { Família } \\
\text { (E) }\end{array}$} & \multicolumn{2}{|c|}{ Importância total } \\
\hline & & & & & & $\begin{array}{l}\text { Efeito Lula } \\
\text { (F) }=(D)- \\
\text { (C) }\end{array}$ & $\begin{array}{l}\text { Efeito Bolsa } \\
\text { Família (G) } \\
=(\mathrm{E})-(\mathrm{C})\end{array}$ \\
\hline CE & 66,29 & 66,40 & 17,00 & 61,41 & 21,99 & 44,41 & 4,98 \\
\hline RN & 51,76 & 52,40 & 10,43 & 47,87 & 14,96 & 37,44 & 4,53 \\
\hline PB & 53,21 & 55,05 & 9,50 & 50,14 & 14,41 & 40,64 & 4,91 \\
\hline PE & 61,74 & 62,73 & 13,72 & 57,92 & 18,53 & 44,20 & 4,81 \\
\hline$A L$ & 50,91 & 50,97 & 16,64 & 45,49 & 22,11 & 28,86 & 5,47 \\
\hline SE & 47,67 & 47,30 & 13,28 & 42,72 & 17,86 & 29,44 & 4,57 \\
\hline BA & 62,62 & 64,29 & 17,89 & 59,44 & 22,73 & 41,56 & 4,84 \\
\hline \multicolumn{8}{|c|}{ Sudeste } \\
\hline MG & 46,98 & 47,70 & 13,72 & 45,37 & 16,05 & 31,66 & 2,33 \\
\hline ES & 37,25 & 39,76 & 4,46 & 37,54 & 6,68 & 33,08 & 2,21 \\
\hline RJ & 43,77 & 40,48 & 8,02 & 38,74 & 9,77 & 30,72 & 1,75 \\
\hline SP & 37,31 & 35,01 & 10,89 & 33,85 & 12,05 & 22,96 & 1,15 \\
\hline \multicolumn{8}{|l|}{ Sul } \\
\hline PR & 38,94 & 41,05 & 15,55 & 39,22 & 17,38 & 23,67 & 1,83 \\
\hline SC & 38,71 & 40,78 & 19,07 & 39,82 & 20,02 & 20,76 & 0,95 \\
\hline RS & 46,92 & 46,91 & 24,61 & 45,18 & 26,34 & 20,57 & 1,73 \\
\hline \multicolumn{8}{|c|}{ Centro-Oeste } \\
\hline MS & 39,86 & 40,03 & 15,36 & 37,82 & 17,57 & 22,46 & 2,21 \\
\hline MT & 42,94 & 43,09 & 16,69 & 40,82 & 18,96 & 24,13 & 2,27 \\
\hline GO & 42,23 & 41,56 & 14,23 & 39,33 & 16,46 & 25,10 & 2,23 \\
\hline DF & 31,74 & 31,74 & 7,07 & 30,17 & 8,64 & 23,10 & 1,57 \\
\hline $\begin{array}{l}\text { Média } \\
\text { país }\end{array}$ & 46,91 & 46,80 & 13,89 & 44,17 & 16,52 & 30,28 & 2,63 \\
\hline
\end{tabular}

Fonte: Elaboração própria.

Nota: cálculo dos autores.

Os resultados corroboram a maior relevância do "efeito Lula" vis-à-vis o "efeito Bolsa Família". Para todos os estados (e municípios), o "efeito Lula", como medido pelo acréscimo em pontos percentuais na votação, foi superior ao "efeito Bolsa Família". Em 
alguns estados, esse efeito supera os 40 pontos percentuais. Isso é particularmente verdade nos estados da região Nordeste (à exceção de Alagoas, Rio Grande do Norte e Sergipe) e no Amazonas. O efeito do Bolsa Família também apresenta uma força maior nos estados da região Nordeste comparativamente aos demais estados da Federação.

A Figura 6 ilustra ainda que, em municípios com menor PIB per capita (painel A) ou com maior proporção de pobres (painel C), a força do "efeito Lula" foi comparativamente superior do que nos municípios mais ricos, e o mesmo se aplica em municípios onde Marina Silva teve votação menor (painel B). O "efeito Bolsa Família" também foi mais forte em municípios com menor PIB per capita (painel D) e com maior proporção de pobres na população (painel F) e naqueles onde a votação de Marina foi menor em 2010 (painel E).

\section{Figura 6}

\section{Efeito Lula e Efeito Bolsa Família versus PIB per capita e Votação de Marina}

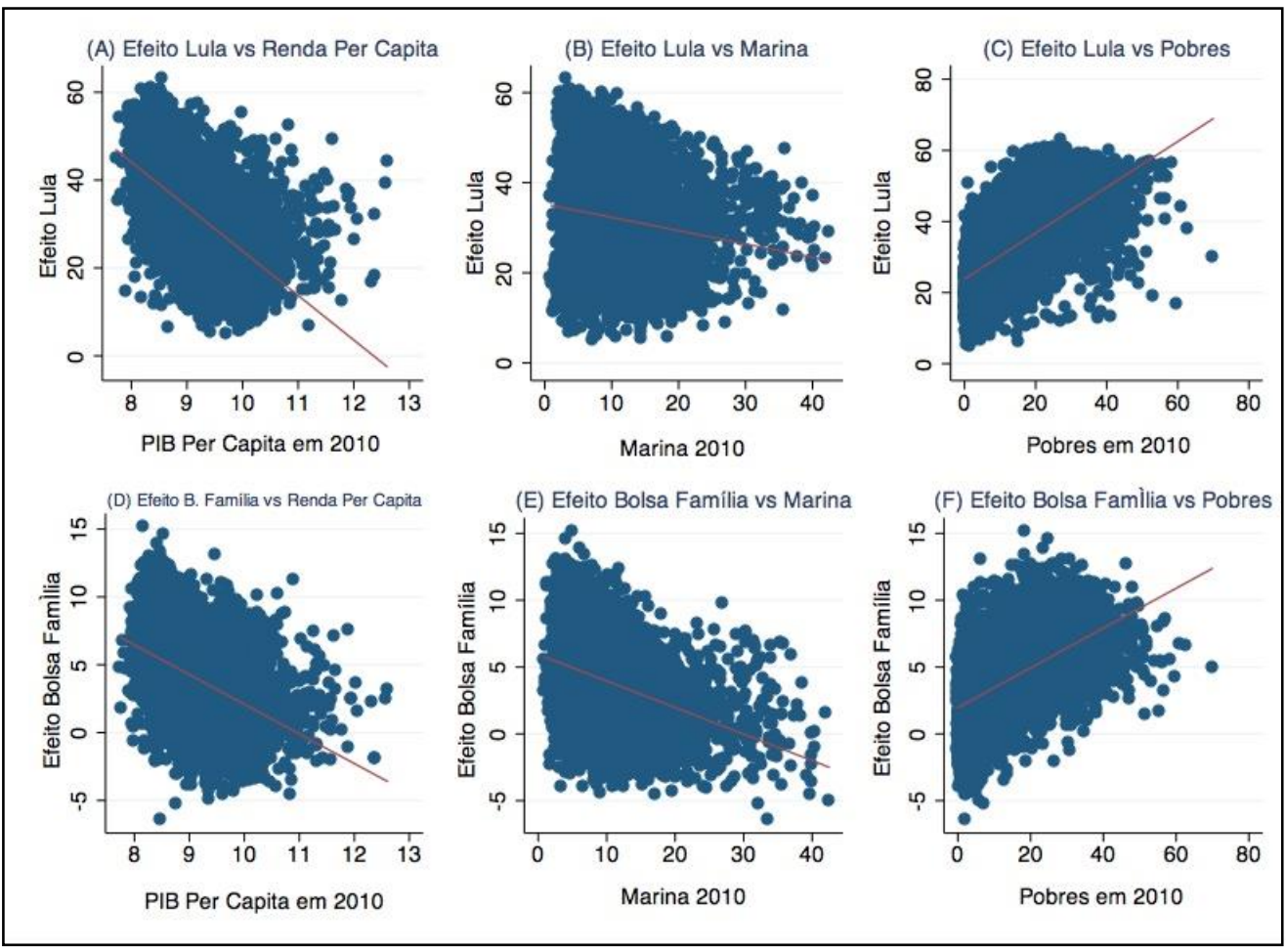

Fonte: Elaboração própria. 


\section{Comentários finais}

A questão inicialmente proposta neste artigo foi relacionada à contribuição do padrinho político de Dilma e seu principal programa de governo na eleição de 2010 . O caminho seguido foi semelhante ao dos demais trabalhos que buscaram entender os determinantes das duas eleições de Lula à presidência. Os modelos estimados consideraram a participação do Bolsa Família nos municípios e a votação obtida por Lula em 2006. Como demais controles foram incluídas características socioeconômicas dos municípios (PIB, população, taxa de urbanização, taxa de analfabetismo, entre outras), características políticas (partidos dos prefeitos dos municípios) e de religião (numa tentativa de identificar algum efeito da presença de Marina no pleito). Como sugere a literatura, a possibilidade de dependência espacial foi devidamente considerada nos modelos finais.

Os resultados indicaram que tanto o Bolsa Família quanto Lula foram importantes na votação de Dilma (tanto no primeiro quanto no segundo turnos). Ou seja, mesmo controlando pela votação obtida por Lula, o BF continuou importante para a eleição de Dilma. É possível interpretar esse resultado como sendo uma consequência do desempenho do segundo mandato de Lula: o aprofundamento do BF na segunda gestão ampliou a sua força além daquela sentida no pleito de 2006 e rendeu mais dividendos eleitorais. O efeito Lula foi, entretanto, maior do que aquele gerado pelo programa. Cabe notar que esse resultado está em acordo com o encontrado por Zucco (2013), no sentido de que o Bolsa Família tem efeitos eleitorais positivos de curto prazo, ajudando na votação do partido incumbente, mas não de longo prazo, não gerando fidelidades a políticos ou partidos.

Ademais, foi possível observar que a votação de Dilma tendeu a ser proporcionalmente maior nos municípios menores, menos urbanizados e com maior taxa de analfabetismo. As prefeituras do PT não foram particularmente favoráveis a Dilma, confirmando um descolamento entre o perfil do seu eleitor e aquele do PT. Cabe notar que esses resultados estão em linha com a mudança observada no perfil do eleitor de Lula entre 2002 e 2006: de um perfil mais disperso para um mais concentrado em municípios menores e mais pobres (com forte participação no Norte e Nordeste).

Pelos resultados obtidos pode-se concluir que a eleição de Dilma em 2010 foi de fato uma segunda reeleição de Lula. Esse fato não vem como uma surpresa, dado o contexto eleitoral à época: Lula conseguiu eleger uma candidata desconhecida do público geral e que enfrentava a sua primeira eleição.

O contexto de 2014 foi distinto. Dilma não era mais desconhecida. Ela teve mais de três anos de gestão pelos quais certamente foi avaliada pelos eleitores. A continuidade de programas como o Bolsa Família e o lançamento de novos programas como Mais Médicos e o Minha Casa Minha Vida certamente reforçaram a relação que o 
eleitor fez entre os governos Dilma e Lula e, apesar de todas as discussões geradas acerca destes dois últimos programas, é fato que eles têm atendido as populações carentes em áreas remotas do país. Dilma venceu a eleição em 2014, por pequena margem e em grande medida por se apresentar como uma candidata de continuidade, rechaçando veementemente qualquer alteração de condução na linha traçada desde seu antecessor. Um futuro exercício interessante será o de avaliar os resultados de 2014 à luz dos instrumentos aqui utilizados, sugerindo possíveis impactos para o próximo certame, em 2018.

André Matos Magalhães - Ph.D. em Economia, Professor Associado do Departamento de Economia. Universidade Federal de Pernambuco (UFPE). E-mail: <magalhs@gmail.com>.

Marcelo Eduardo Alves da Silva - Ph.D. em Economia, Professor Adjunto do Departamento de Economia. Universidade Federal de Pernambuco (UFPE).

E-mail: <measilva@gmail.com>.

Fernando de Mendonça Dias - Doutor em Economia, Professor Adjunto do Departamento de Economia. Universidade Federal de Pernambuco (UFPE).

E-mail: <fernandomdias@gmail.com>.

\section{Referências bibliográficas}

Abensur, T. C.; Cribari-Neto, F.; Menezes, T. A. "Impactos do programa Bolsa Família nos resultados das eleições presidenciais no Brasil em 2006". In: Anais do XXXV Encontro Nacional de Economia, 2007. Recife: Anpec, p. 1-16, 2007.

ANSELIN, L. Spatial econometrics: methods and models. Dordrecht: Kluwer Academic, 1988.

ANSELIN, L.; BERA, A. K. "Spatial dependence in linear regression models with an introduction to spatial econometrics". Statistics Textbooks and Monographs, vol. 155, p. 237-290, 1998.

CANÊDo-Pinheiro, M. "Bolsa Família ou desempenho da economia? Determinantes da reeleição de Lula em 2006". In: Anais do XXXVII Encontro Nacional de Economia, 2009. Recife: Anpec, p. 1-20, 2009.

CASE, A. C.; Rosen, H. S.; Hines JR., J. R. "Budget spillovers and fiscal policy interdependence: evidence from the states". Journal of Public Economics, vol. 52, p. 285-307, 1993.

CERDA, R.; VERGARA, R. "Government subsidies and presidential election outcomes: evidence for a developing country". World Development, vol. 36, $\mathrm{n}^{\circ} 11$, p. 2.470-2.488, 2008.

CLIFF, A. D.; ORD, J. K. Spatial autocorrelation. London: Pion, 1973. . Spatial processes: models and applications. London: Pion, 1981.

DE LA O, A. "Do conditional cash transfers affect electoral behavior? Evidence from a randomized experiment in Mexico". American Journal of Political Science, vol. 57, p. 1-14, 2013.

GueRvós, R. C., Aproximación al valor de la vivienda: aplicación a la ciudad de Granada. Granada: Editorial Universidade de Granada, 1999. 
Hunter, W.; Power, T. J. "Rewarding Lula: Executive Power, social policy, and the Brazilian elections of 2006". Latin American Politics and Society, vol. 49, n 1, p. 1-30, abr. 2007.

LABONNE, J. "The local electoral impacts of conditional cash transfers: evidence from a field experiment". Journal of Development Economics, vol. 104, p. 73-88, 2013.

Manacorda, M.; Miguel, E.; Vigorito, A. "Government transfers and political support". American Economic Journal: Applied Economics, vol. 3, n 3, p. 1-28, 2011.

Marzagão, T. "A dimensão geográfica das eleições brasileiras". Opinião Pública, Campinas, vol. 19, $\mathrm{n}^{\circ} 2$, p. 270-290, nov. 2013.

Nicolau, J.; Peixoto, V. As bases municipais da votação de Lula em 2006. In: Reis Velloso, J. P. (coord.). Quem elegeu Lula? Cadernos do Fórum Nacional, nº 6, fev. 2007.

SHIKIDA, C. D., et al. "It is the economy, companheiro!: an empirical analysis of Lula's re-election based on municipal data". Economics Bulletin, vol. 29, n² 2, p. 976-991, 2009.

SOARES, F. V., et al. "Cash transfer programmes in Brazil: impacts on inequality and poverty". UNDP International Poverty Centre, Working Paper, $\mathrm{n}^{\circ}$ 21, jun. 2006.

SoARES, G. A. D.; TerRon, S. L. "Dois Lulas: a geografia eleitoral da reeleição (explorando conceitos, métodos e técnicas de análise geoespacial)". Opinião Pública, Campinas, vol. 14, n 2, p. 269-301, nov. 2008.

SoARES, S. "Bolsa Família, its design, its impacts and possibilities for the future". In: The International Policy Centre for Inclusive Growth, Working Paper, n 89, fev. 2012

StOKeR, T. M. "Empirical approaches to the problem of aggregation over individuals". Journal of Economic Literature, vol. 31, p. 1.827-1.874, 1993.

Zucco, C. "The president's 'new' constituency: Lula and the pragmatic vote in Brazil's 2006 presidential elections". Journal of Latin American Studies, vol. 40, p. 29-39, 2008.

"When payouts pay off: conditional cash transfers and voting behavior in Brazil 2002-

10". American Journal of Political Science, vol. 57, n 4, p. 810-822, 2013. 


\section{Anexos}

Tabela A1

Resultado das regressões (OLS) para proporção de votos em Dilma no segundo turno de 2010

Variável dependente: votação de Dilma no segundo turno de 2010

\begin{tabular}{|c|c|c|c|c|}
\hline & $\begin{array}{c}\text { (1) } \\
\text { dilma_10_2 }\end{array}$ & $\begin{array}{c}(2) \\
\text { dilma_10_2 }\end{array}$ & $\begin{array}{c}\text { (3) } \\
\text { dilma_10_2 }\end{array}$ & $\begin{array}{c}\text { (4) } \\
\text { dilma_10_2 }\end{array}$ \\
\hline BF_sh_10 & $\begin{array}{c}1,481 * * * \\
(29,21)\end{array}$ & $\begin{array}{c}0,475^{* * *} \\
(13,90)\end{array}$ & $\begin{array}{c}0,246 * * * \\
(5,50)\end{array}$ & $\begin{array}{c}0,203 * * * \\
(4,61)\end{array}$ \\
\hline lula_06_1 & & $\begin{array}{c}0,724 * * * \\
(79,49)\end{array}$ & $\begin{array}{c}0,736 * * * \\
(82,56)\end{array}$ & $\begin{array}{c}0,741 * * * \\
(83,41)\end{array}$ \\
\hline pref_pt & & & $\begin{array}{c}-3,359 * * * \\
(-11,97)\end{array}$ & $\begin{array}{c}-3,430 * * * \\
(-12,21)\end{array}$ \\
\hline pref_pmdb & & & $\begin{array}{l}-0,275 \\
(-1,28)\end{array}$ & $\begin{array}{l}-0,277 \\
(-1,30)\end{array}$ \\
\hline pref_psdb & & & $\begin{array}{l}0,0536 \\
(0,28)\end{array}$ & $\begin{array}{c}0,00965 \\
(0,05)\end{array}$ \\
\hline Inpibpc10 & & & $\begin{array}{l}0,256 \\
(1,29)\end{array}$ & $\begin{array}{l}0,309 \\
(1,57)\end{array}$ \\
\hline Inpop10 & & & $\begin{array}{c}-0,203 * * \\
(-2,10)\end{array}$ & $\begin{array}{c}0,000784 \\
(0,01)\end{array}$ \\
\hline Dens_2010 & & & $\begin{array}{c}0,000890 * * * \\
(6,47)\end{array}$ & $\begin{array}{c}0,00105^{* * *} \\
(6,95)\end{array}$ \\
\hline tx_urb & & & $\begin{array}{c}-0,0504 * * * \\
(-9,00)\end{array}$ & $\begin{array}{c}-0,0429 * * * \\
(-7,66)\end{array}$ \\
\hline Gini_10 & & & $\begin{array}{c}-6,938 * * * \\
(-4,14)\end{array}$ & $\begin{array}{c}-6,530 * * * \\
(-3,94)\end{array}$ \\
\hline \multirow[t]{2}{*}{ Analf_10 } & & & $-0,0731 * * *$ & $-0,123 * * *$ \\
\hline & & & $(-2,86)$ & $(-4,73)$ \\
\hline tx_mort_10 & & & $\begin{array}{c}0,00387 \\
(0,64)\end{array}$ & $\begin{array}{c}0,00378 \\
(0,65)\end{array}$ \\
\hline pobres_share & & & $\begin{array}{c}0,112 * * * \\
(6,56)\end{array}$ & $\begin{array}{c}0,106 * * * \\
(6,26)\end{array}$ \\
\hline
\end{tabular}




\begin{tabular}{|c|c|c|c|c|}
\hline & $\begin{array}{c}\text { (1) } \\
\text { dilma_10_2 }\end{array}$ & $\begin{array}{c}\text { (2) } \\
\text { dilma_10_2 }\end{array}$ & $\begin{array}{c}\text { (3) } \\
\text { dilma_10_2 }\end{array}$ & $\begin{array}{c}\text { (4) } \\
\text { dilma_10_2 }\end{array}$ \\
\hline sh_evang & & & $\begin{array}{l}-0,0192 \\
(-1,04)\end{array}$ & $\begin{array}{l}-0,0133 \\
(-0,73)\end{array}$ \\
\hline sh_cato & & & $\begin{array}{c}0,00587 \\
(0,33)\end{array}$ & $\begin{array}{c}-0,00648 \\
(-0,37)\end{array}$ \\
\hline sh_semrel & & & $\begin{array}{c}-0,137 * * * \\
(-4,33)\end{array}$ & $\begin{array}{c}-0,122 * * * \\
(-3,94)\end{array}$ \\
\hline marina_10 & & & & $\begin{array}{c}-0,198 * * * \\
(-9,05)\end{array}$ \\
\hline Constante & $\begin{array}{c}38,57 * * * \\
(91,46)\end{array}$ & $\begin{array}{c}17,66 * * * \\
(50,45)\end{array}$ & $\begin{array}{c}25,99 * * * \\
(9,09)\end{array}$ & $\begin{array}{c}26,78 * * * \\
(9,39)\end{array}$ \\
\hline Observações & 5565 & 5565 & 5555 & 5555 \\
\hline R-quadrado & 0,647 & 0,849 & 0,864 & 0,866 \\
\hline $\begin{array}{l}\text { R-quadrado } \\
\text { Ajustado }\end{array}$ & 0,646 & 0,849 & 0,863 & 0,865 \\
\hline
\end{tabular}

Fonte: Elaboração própria.

Estatísticas t entre parênteses.

Significância: $* \mathrm{p}<0,10, * * \mathrm{p}<0,05, * * * \mathrm{p}<0,01$.

Nota: as dummies estaduais foram omitidas por economia de espaço, mas estão disponíveis por solicitação aos autores. Todos os modelos foram estimados por mínimos quadrados ordinários com correção para heterocedasticidade. 
ANDRÉ MATOS MAGALHÃES; MARCELO EDUARDO ALVES DA SILVA; FERNANDO DE MENDONÇA DIAS

Tabela A2

Resultados das regressões para a votação de Marina no primeiro turno de 2010

\begin{tabular}{|c|c|c|c|}
\hline & $\begin{array}{c}\text { (1) } \\
\text { marina_10 }\end{array}$ & $\begin{array}{c}\text { (2) } \\
\text { marina_10 }\end{array}$ & $\begin{array}{c}\text { (3) } \\
\text { marina_10 }\end{array}$ \\
\hline BF_sh_10 & $\begin{array}{c}-0,861 * * * \\
(-29,63)\end{array}$ & $\begin{array}{c}-0,924 * * * \\
(-28,84)\end{array}$ & $\begin{array}{c}-0,215^{* * * *} \\
(-7,62)\end{array}$ \\
\hline lula_06_1 & & $\begin{array}{c}0,0455^{* * * *} \\
(7,06)\end{array}$ & $\begin{array}{c}0,0222 * * * \\
(4,39)\end{array}$ \\
\hline pref_pt & & & $\begin{array}{c}-0,359 * * \\
(-2,02)\end{array}$ \\
\hline pref_pmdb & & & $\begin{array}{c}-0,0135 \\
(-0,10)\end{array}$ \\
\hline pref_psdb & & & $\begin{array}{l}-0,222 * \\
(-1,88)\end{array}$ \\
\hline Inpibpc10 & & & $\begin{array}{c}0,268 * \\
(1,82)\end{array}$ \\
\hline Inpop10 & & & $\begin{array}{c}1,031 * * * \\
(14,77)\end{array}$ \\
\hline Dens_2010 & & & $\begin{array}{c}0,000784 * * * \\
(4,26)\end{array}$ \\
\hline tx_urb & & & $\begin{array}{c}0,0379 * * * \\
(12,11)\end{array}$ \\
\hline Gini_10 & & & $\begin{array}{l}2,060 * \\
(1,84)\end{array}$ \\
\hline Analf_10 & & & $\begin{array}{c}-0,253^{* * *} \\
(-17,05)\end{array}$ \\
\hline tx_mort_10 & & & $\begin{array}{c}-0,000455 \\
(-0,11)\end{array}$ \\
\hline pobres_share & & & $\begin{array}{c}-0,0300 * * * \\
(-2,92)\end{array}$ \\
\hline sh_evang & & & $\begin{array}{c}0,0296 * * \\
(2,38)\end{array}$ \\
\hline
\end{tabular}




\begin{tabular}{|c|c|c|c|}
\hline & $\begin{array}{c}\text { (1) } \\
\text { marina_10 }\end{array}$ & $\begin{array}{c}\text { (2) } \\
\text { marina_10 }\end{array}$ & $\begin{array}{c}(3) \\
\text { marina_10 }\end{array}$ \\
\hline sh_cato & & & $\begin{array}{c}-0,0624 * * * \\
(-5,12)\end{array}$ \\
\hline sh_semrel & & & $\begin{array}{c}0,0734 * * * \\
(3,33)\end{array}$ \\
\hline Constante & $\begin{array}{c}19,15^{* * *} \\
(82,84)\end{array}$ & $\begin{array}{c}17,84 * * * \\
(65,24)\end{array}$ & $\begin{array}{c}3,998^{*} \\
(1,87)\end{array}$ \\
\hline Observações & 5565 & 5565 & 5555 \\
\hline R-quadrado & 0,478 & 0,483 & 0,682 \\
\hline $\begin{array}{l}\text { R-quadrado } \\
\text { Ajustado }\end{array}$ & 0,476 & 0,481 & 0,679 \\
\hline
\end{tabular}

Fonte: Elaboração própria.

Estatísticas t entre parênteses.

Significância: $* \mathrm{p}<0,10, * * \mathrm{p}<0,05, * * * \mathrm{p}<0,01$.

Nota: as dummies estaduais foram omitidas por economia de espaço, mas estão disponíveis por solicitação aos autores. Todos os modelos foram estimados por mínimos quadrados ordinários com correção para heterocedasticidade. 
Tabela A3

Coeficientes estimados para as dummies estaduais nos três modelos de Cross-Section para a votação de Dilma no primeiro turno de 2010

\begin{tabular}{|c|c|c|c|}
\hline & $\begin{array}{c}(1) \\
\text { dilma_10_1 }\end{array}$ & $\begin{array}{c}\text { (2) } \\
\text { dilma_10_1 }\end{array}$ & $\begin{array}{c}\text { (3) } \\
\text { dilma_10_1 }\end{array}$ \\
\hline \multicolumn{4}{|c|}{ Região Norte } \\
\hline RO & $\begin{array}{c}-5,095 * * * \\
(-5,26)\end{array}$ & $\begin{array}{c}-5,359 * * * \\
(-9,37)\end{array}$ & $\begin{array}{c}-3,174 * * * \\
(-5,25)\end{array}$ \\
\hline$A C$ & $\begin{array}{c}-15,94 * * * \\
(-7,33)\end{array}$ & $\begin{array}{c}-17,85 * * * \\
(-10,05)\end{array}$ & $\begin{array}{c}-18,38 * * * \\
(-12,63)\end{array}$ \\
\hline AM & $\begin{array}{c}27,26 * * * \\
(21,51)\end{array}$ & $\begin{array}{c}5,108 * * * \\
(4,81)\end{array}$ & $\begin{array}{c}2,400 * * \\
(2,23) \\
\end{array}$ \\
\hline $\mathrm{RR}$ & $\begin{array}{c}-14,91 * * * \\
(-6,87)\end{array}$ & $\begin{array}{c}-7,831 * * * \\
(-6,39)\end{array}$ & $\begin{array}{c}-8,331 * * * \\
(-5,04)\end{array}$ \\
\hline PA & $\begin{array}{c}3,868 * * * \\
(4,02)\end{array}$ & $\begin{array}{c}-2,205 * * * \\
(-3,08)\end{array}$ & $\begin{array}{c}-2,810 * * * \\
(-3,97)\end{array}$ \\
\hline AP & $\begin{array}{c}13,48 * * * \\
(8,09)\end{array}$ & $\begin{array}{l}-1.532 \\
(-1,36)\end{array}$ & $\begin{array}{l}-1,755^{*} \\
(-1,75) \\
\end{array}$ \\
\hline TO & $\begin{array}{c}5,005 * * * \\
(6,16)\end{array}$ & $\begin{array}{c}-3,256 * * * \\
(-4,44)\end{array}$ & $\begin{array}{c}-3,537 * * * \\
(-4,93)\end{array}$ \\
\hline \multicolumn{4}{|c|}{ Região Nordeste } \\
\hline MA & $\begin{array}{c}18,57 * * * \\
(20,26)\end{array}$ & $\begin{array}{l}0,642 \\
(0,92)\end{array}$ & $\begin{array}{l}-1.081 \\
(-1,55)\end{array}$ \\
\hline PI & $\begin{array}{c}13,35 * * * \\
(14,03)\end{array}$ & $\begin{array}{c}1,902 * * * \\
(2,67)\end{array}$ & $\begin{array}{l}-0,510 \\
(-0,75)\end{array}$ \\
\hline $\mathrm{CE}$ & $\begin{array}{c}16,65 * * * \\
(19,93)\end{array}$ & $\begin{array}{c}1,962 * * * \\
(2,90)\end{array}$ & $\begin{array}{l}0,636 \\
(0,96) \\
\end{array}$ \\
\hline RN & $\begin{array}{c}4,711 * * * \\
(4,57)\end{array}$ & $\begin{array}{c}-7,101 * * * \\
(-10,07)\end{array}$ & $\begin{array}{c}-7,719 * * * \\
(-10,80)\end{array}$ \\
\hline PB & $\begin{array}{c}5,454^{* * *} \\
(5,86)\end{array}$ & $\begin{array}{c}-7,391 * * * \\
(-10,75)\end{array}$ & $\begin{array}{c}-9,538 * * * \\
(-13,73)\end{array}$ \\
\hline PE & $\begin{array}{c}16,59 * * * \\
(16,91)\end{array}$ & $\begin{array}{l}-0,519 \\
(-0,66)\end{array}$ & $\begin{array}{l}-0,336 \\
(-0,46)\end{array}$ \\
\hline$A L$ & $\begin{array}{l}1.359 \\
(0,92)\end{array}$ & $\begin{array}{c}-2,125^{* *} \\
(-2,17)\end{array}$ & $\begin{array}{l}-1,589 * \\
(-1,88)\end{array}$ \\
\hline
\end{tabular}




\begin{tabular}{|c|c|c|c|}
\hline & $\begin{array}{c}(1) \\
\text { dilma_10_1 }\end{array}$ & $\begin{array}{c}\text { (2) } \\
\text { dilma_10_1 }\end{array}$ & $\begin{array}{c}\text { (3) } \\
\text { dilma_10_1 }\end{array}$ \\
\hline SE & $\begin{array}{l}-0,948 \\
(-0,91)\end{array}$ & $\begin{array}{c}-2,311 * * * \\
(-2,90)\end{array}$ & $\begin{array}{c}-1,878 * * \\
(-2,28)\end{array}$ \\
\hline BA & $\begin{array}{c}12,10 * * * \\
(15,81)\end{array}$ & $\begin{array}{l}0,867 \\
(1,39)\end{array}$ & $\begin{array}{c}1,754 * * * \\
(3,04)\end{array}$ \\
\hline \multicolumn{4}{|c|}{ Região Sudeste } \\
\hline MG & $\begin{array}{c}7,831 * * * \\
(14,77)\end{array}$ & $\begin{array}{c}0,740 * * \\
(1,98)\end{array}$ & $\begin{array}{l}-0,183 \\
(-0,49)\end{array}$ \\
\hline ES & $\begin{array}{c}-2,807 * * * \\
(-2,69)\end{array}$ & $\begin{array}{c}-11,99 * * * \\
(-16,29)\end{array}$ & $\begin{array}{c}-10,96 * * * \\
(-15,95)\end{array}$ \\
\hline RJ & $\begin{array}{l}-0,114 \\
(-0,12)\end{array}$ & $\begin{array}{c}-7,528 * * * \\
(-12,69)\end{array}$ & $\begin{array}{c}-3,735 * * * \\
(-5,72)\end{array}$ \\
\hline \multicolumn{4}{|l|}{ Região Sul } \\
\hline PR & $\begin{array}{c}5,598 * * * \\
(9,67)\end{array}$ & $\begin{array}{c}2,222 * * * \\
(5,52)\end{array}$ & $\begin{array}{l}0,743^{*} \\
(1,96)\end{array}$ \\
\hline SC & $\begin{array}{c}9,316 * * * \\
(14,59)\end{array}$ & $\begin{array}{c}8,268 * * * \\
(18,75)\end{array}$ & $\begin{array}{c}4,376 * * * \\
(10,33)\end{array}$ \\
\hline RS & $\begin{array}{c}11,26 * * * \\
(21,22)\end{array}$ & $\begin{array}{c}12,77 * * * \\
(33,78)\end{array}$ & $\begin{array}{c}9,892 * * * \\
(26,51)\end{array}$ \\
\hline \multicolumn{4}{|c|}{ Região Centro-Oeste } \\
\hline MS & $\begin{array}{l}0,936 \\
(1,24)\end{array}$ & $\begin{array}{c}1,297 * * * \\
(2,72)\end{array}$ & $\begin{array}{c}2,238 * * * \\
(4,43)\end{array}$ \\
\hline MT & $\begin{array}{l}1.074 \\
(1,38)\end{array}$ & $\begin{array}{c}2,541 * * * \\
(4,61)\end{array}$ & $\begin{array}{c}2,541 * * * \\
(4,62)\end{array}$ \\
\hline GO & $\begin{array}{c}2,626 * * * \\
(4,09)\end{array}$ & $\begin{array}{c}1,496 * * * \\
(3,25)\end{array}$ & $\begin{array}{c}2,569 * * * \\
(5,64)\end{array}$ \\
\hline DF & $\begin{array}{c}-5,733 * * * \\
(-16,85)\end{array}$ & $\begin{array}{c}-7,566 * * * \\
(-36,50)\end{array}$ & $\begin{array}{c}-2,324 * * * \\
(-4,13)\end{array}$ \\
\hline Observações & 5565 & 5565 & 5555 \\
\hline R-quadrado & 0,672 & 0,821 & 0,856 \\
\hline $\begin{array}{l}\text { R-quadrado } \\
\text { Ajustado }\end{array}$ & 0,670 & 0,820 & 0,855 \\
\hline
\end{tabular}

Fonte: Elaboração própria.

Estatísticas t entre parênteses.

Significância: * $\mathrm{p}<0,10, * * \mathrm{p}<0,05, * * * \mathrm{p}<0,01$.

Nota: Todos os modelos foram estimados por mínimos quadrados ordinários com correção para heterocedasticidade. Os resultados das dummies estaduais tomam como referência o estado de São Paulo. 
Tabela A4

Coeficientes estimados para as dummies estaduais do modelo de erro espacial para proporção de votos em Dilma no primeiro turno de 2010

\begin{tabular}{|c|c|c|c|c|}
\hline Variáveis & Coeficientes & Desvio-padrão & Valor z & Probabilidade \\
\hline \multicolumn{5}{|l|}{ Região Norte } \\
\hline RO & $-1,4307$ & 1,8717 & $-0,7644$ & 0,4446 \\
\hline$A C$ & $-15,5952$ & 2,2902 & $-6,8096$ & 0,0000 \\
\hline AM & 4,4782 & 1,5904 & 2,8157 & 0,0049 \\
\hline $\mathrm{RR}$ & $-4,3565$ & 2,8757 & $-1,5149$ & 0,1298 \\
\hline PA & $-0,1516$ & 1,1784 & $-0,1286$ & 0,8976 \\
\hline AP & $-1,8670$ & 2,6894 & $-0,6942$ & 0,4875 \\
\hline TO & $-2,9003$ & 1,2121 & $-2,3929$ & 0,0167 \\
\hline \multicolumn{5}{|c|}{ Região Nordeste } \\
\hline MA & 0,9894 & 1,1335 & 0,8729 & 0,3827 \\
\hline PI & 1,3166 & 1,0602 & 1,2418 & 0,2143 \\
\hline CE & 1,4934 & 1,1056 & 1,3508 & 0,1768 \\
\hline RN & $-6,0822$ & 1,1086 & $-5,4866$ & 0,0000 \\
\hline PB & $-7,7188$ & 1,0238 & $-7,5392$ & 0,0000 \\
\hline $\mathrm{PE}$ & 0,2339 & 1,0584 & 0,2210 & 0,8251 \\
\hline $\mathrm{AL}$ & $-0,7698$ & 1,3086 & $-0,5883$ & 0,5564 \\
\hline SE & $-3,7081$ & 1,4096 & $-2,6306$ & 0,0085 \\
\hline BA & 3,3063 & 0,9228 & 3,5830 & 0,0003 \\
\hline \multicolumn{5}{|l|}{ Região Sudeste } \\
\hline MG & 1,0764 & 0,6417 & 1,6774 & 0,0935 \\
\hline ES & $-7,1401$ & 1,3586 & $-5,2555$ & 0,0000 \\
\hline RJ & $-3,3897$ & 1,2284 & $-2,7595$ & 0,0058 \\
\hline \multicolumn{5}{|l|}{ Região Sul } \\
\hline PR & 2,7915 & 0,8156 & 3,4228 & 0,0006 \\
\hline SC & 6,7672 & 0,8571 & 7,8956 & 0,0000 \\
\hline RS & 12,3407 & 0,7555 & 16,3341 & 0,0000 \\
\hline
\end{tabular}




\begin{tabular}{|l|c|c|c|c|}
\hline \multicolumn{1}{|c|}{ Variáveis } & Coeficientes & Desvio-padrão & Valor $\mathbf{z}$ & Probabilidade \\
\hline Região Centro-Oeste \\
\hline MS & 2,7907 & 1,4723 & 1,8955 & 0,0580 \\
\hline MT & 2,9450 & 1,1536 & 2,5529 & 0,0107 \\
\hline GO & 2,3620 & 0,9596 & 2,4613 & 0,0138 \\
\hline DF & $-1,0192$ & 5,2034 & $-0,1959$ & 0,8447 \\
\hline $\begin{array}{l}|c| \\
\text { R-quadrado }\end{array}$ Verossimilhança \\
$\begin{array}{l}\text { Critério de informação de Akaike } \\
\text { Critério de Schwarz }\end{array}$ \\
\hline
\end{tabular}

Fonte: Elaboração própria. 
Tabela A5

Coeficientes estimados para as dummies estaduais do modelo de erro espacial para proporção de votos em Dilma no segundo turno de 2010

\begin{tabular}{|c|c|c|c|c|}
\hline Variáveis & Coeficientes & Desvio-padrão & Valor z & Probabilidade \\
\hline \multicolumn{5}{|l|}{ Região Norte } \\
\hline RO & $-5,5398$ & 1,6251 & $-3,4089$ & 0,0007 \\
\hline$A C$ & $-15,6628$ & 2,0106 & $-7,7899$ & 0,0000 \\
\hline AM & 1,7020 & 1,3890 & 1,2253 & 0,2205 \\
\hline $\mathrm{RR}$ & $-10,7583$ & 2,5205 & $-4,2683$ & 0,0000 \\
\hline PA & $-3,3087$ & 1,0306 & $-3,2106$ & 0,0013 \\
\hline $\mathrm{AP}$ & 1,0428 & 2,3662 & 0,4407 & 0,6594 \\
\hline TO & $-3,4231$ & 1,0550 & $-3,2446$ & 0,0012 \\
\hline \multicolumn{5}{|c|}{ Região Nordeste } \\
\hline MA & 0,8112 & 0,9903 & 0,8192 & 0,4127 \\
\hline PI & $-0,1510$ & 0,9340 & $-0,1617$ & 0,8715 \\
\hline $\mathrm{CE}$ & 1,6781 & 0,9731 & 1,7245 & 0,0846 \\
\hline RN & $-4,1064$ & 0,9755 & $-4,2094$ & 0,0000 \\
\hline PB & $-4,8635$ & 0,9021 & $-5,3915$ & 0,0000 \\
\hline $\mathrm{PE}$ & 2,6562 & 0,9270 & 2,8654 & 0,0042 \\
\hline $\mathrm{AL}$ & $-4,8592$ & 1,1524 & $-4,2167$ & 0,0000 \\
\hline SE & $-4,2273$ & 1,2367 & $-3,4183$ & 0,0006 \\
\hline $\mathrm{BA}$ & 0,1104 & 0,8086 & 0,1366 & 0,8914 \\
\hline \multicolumn{5}{|c|}{ Região Sudeste } \\
\hline MG & $-0,2123$ & 0,5658 & $-0,3752$ & 0,7076 \\
\hline ES & $-8,4737$ & 1,1891 & $-7,1262$ & 0,0000 \\
\hline RJ & $-3,4073$ & 1,0912 & $-3,1225$ & 0,0018 \\
\hline \multicolumn{5}{|l|}{ Região Sul } \\
\hline PR & $-1,8540$ & 0,7110 & $-2,6075$ & 0,0091 \\
\hline SC & 0,0997 & 0,7544 & 0,1322 & 0,8948 \\
\hline RS & 5,0641 & 0,6743 & 7,5102 & 0,0000 \\
\hline
\end{tabular}




\begin{tabular}{|l|r|r|r|r|}
\hline \multicolumn{1}{|c|}{ Variáveis } & Coeficientes & Desvio-padrão & Valor z & Probabilidade \\
\hline \multicolumn{5}{|c|}{ Região Centro-Oeste } \\
\hline MS & 0,5030 & 1,2777 & 0,3937 & 0,6938 \\
\hline MT & $-0,7968$ & 1,0065 & $-0,7916$ & 0,4286 \\
\hline GO & $-2,7008$ & 0,8324 & $-3,2445$ & 0,0012 \\
\hline DF & 8,7498 & 4,7586 & 1,8387 & 0,0660 \\
\hline R-quadrado & \multicolumn{5}{|c|}{0,9070} \\
Verossimilhança & $-16726,2$ & \\
Critério de informação de Akaike & 33540,5 \\
Critério de Schwarz
\end{tabular}

Fonte: Elaboração própria.

\section{Resumo}

Eleição de Dilma ou segunda reeleição de Lula? Uma análise espacial do pleito de 2010

Muito foi dito a respeito do papel do Bolsa Família na eleição de Lula em 2006 e na mudança do perfil do seu eleitor. Pouco foi dito, entretanto, a respeito do papel de Lula e do Bolsa Família com relação à votação de Dilma em 2010. Através de uma abordagem econométrico-espacial, neste artigo nós avaliamos a importância desses e de outros fatores no desempenho eleitoral de Dilma. Após uma nova eleição na qual Dilma enfrentou novos candidatos, é interessante tentar entender quais fatores tiveram maior peso em sua eleição anterior e como isso pode ser visto à luz do atual cenário. A análise é realizada a partir de dados agregados para os municípios, considerando-se as proporções de votos dos candidatos e informações socioeconômicas municipais (renda per capita, percentual de pessoas no Bolsa Família no município, percentual de pobres, percentual de analfabetos, grau de urbanização do município, entre outras). Os resultados indicam uma participação decisiva do ex-presidente Lula e também do Bolsa Família. Ou seja, mesmo controlando pela votação obtida por Lula, o BF continuou importante para a eleição de Dilma. O efeito Lula foi, entretanto, maior do que aquele gerado pelo Programa. Cabe notar que esse resultado está em acordo com o encontrado por Zucco (2013), no sentido de que o Bolsa Família tem efeitos eleitorais positivos de curto prazo, ajudando na votação do partido incumbente, mas não de longo prazo, não gerando fidelidades a políticos ou partidos.

Palavras-chave: Bolsa Família; eleições; Lula

\section{Abstract}

Dilma's election or Lula's second reelection? A spatial analysis of 2010

Much has been said about the role of "Bolsa Família" in the Presidential election of Lula in 2006 and the change of his voter profile. However, little has been said about the effects of Lula's support and "Bolsa Família" on Dilma's electoral performance in the 2010 Presidential elections. Using a spatial econometrics's approach in this paper we evaluate the importance of these (and other) factors on Dilma and her opponents' electoral performance in the 1st round of 2010 elections. It is interesting to understand what factors had more weight on her previous election and how this can be seen in the light of the current scenario. Aggregated data at the municipality level are used in the analysis, considering variables such as candidates' share of total votes and socioeconomics indicators (per capita income, proportion of beneficiaries of "Bolsa Família", percentage of poor, rate of illiteracy, among others). The results indicate a decisive participation of former President Lula and the Bolsa Família Program. Even controlling for Lula's share of votes in the previous election, the "Bolsa Família" Program remains significant for Dilma's election. The Lula's effects, however, was larger than the one found for the Program. It is worth noting that this results in line with the one indicated by Zucco (2013), in the sense that the "Bolsa Família" shows positive 
short run electoral effects, helping the incumbent party, but shows no long run effects, with the loyalties to parties and/or persons.

Keywords: Bolsa Família; elections; Lula

\section{Resumen}

¿Elección de Dilma o la segunda reelección de Lula? Un análisis espacial de la elección de 2010

Mucho se ha discutido sobre el papel del programa "Bolsa Família" en la elección de Lula en 2006 y sobre el cambio en el perfil de sus votantes. No obstante, poco se ha mencionado sobre los efectos del apoyo de Lula y del "Bolsa Família" en las elecciones de 2010. Utilizando el enfoque de una econometría espacial, en este estudio se evalúa la importancia de estos y otros factores en el desempeño electoral de Dilma. Ante una nueva elección, en la cual Dilma enfrentó nuevos candidatos, es interesante analizar qué factores tuvieron una mayor importancia en su elección previa y como esto puede ser visto a la luz de la situación actual. Se realizó el análisis a partir de datos agregados a nivel municipal, teniendo en cuenta variables como la proporción de votos de los candidatos e indicadores socioeconómicos municipales (ingreso per cápita, proporción de beneficiarios del "Bolsa Família", porcentaje de pobres, tasa de analfabetismo, nivel de urbanización del municipio, entre otros). Los resultados indican una participación decisiva del expresidente Lula y del programa "Bolsa Família". De hecho, aun controlando la elección gracias a los votos obtenidos por Lula, el "Bolsa Familia" siguió siendo importante para la elección de Dilma. El efecto Lula, sin embargo, fue mayor que el generado por el Programa. Vale la pena señalar que este resultado está en consonancia con lo indicado por Zucco (2013), en el sentido de que el "Bolsa Família" muestra efectos electorales positivos, en el corto plazo, ayudando al partido ya en el gobierno, pero no en el largo plazo, ya que no genera lealtades a los políticos o a los partidos.

Palabras clave: Bolsa Familia; elecciones; Lula

\section{Résumé}

Élection de Dilma ou deuxième réélection de Lula? Une analyse spatiale de l'élection de 2010

Beaucoup a été dit sur le rôle du programme "Bolsa Família" dans l'élection de Lula en 2006 et sur le changement du profil de son électorat. Peu a été dit, cependant, sur le rôle de Lula et de la "Bolsa Família" concernant I'élection de Dilma en 2010. En utilisant une approche par I'économétrie spatiale, nous avons évalué l'importance de ces facteurs et d'autres encore dans la performance électorale de Dilma. Après une nouvelle élection, au cours de laquelle Dilma a été confrontée à de nouveaux candidats, il est intéressant d'essayer de comprendre quels facteurs ont le plus pesé dans son élection précédente et comment cela peut être vu à la lumière du scénario actuel. L'analyse est réalisée à partir des données agrégées par les communes, en tenant compte du pourcentage de votes obtenu par chaque candidat et des indicateurs socioéconomiques des communes (revenu par habitant, proportion de bénéficiaires de la "Bolsa Família" dans la commune, pourcentage de pauvres, taux d'analphabétisme, entre autres). Les résultats indiquent une participation décisive de l'ancien président Lula et aussi du programme "Bolsa Família". Ainsi, bien qu'il y ait un certain contrôle de la situation grâce aux votes obtenus par Lula, le programme "Bolsa Família" reste important pour l'élection de Dilma. L'effet Lula, cependant, a été supérieur à celui du Programme. Il est à noter que ce résultat coïncide avec celui indiqué par Zucco (2013), dans le sens où la Bourse Famille a des effets électoraux positifs à court terme, elle incite à voter pour le parti au pouvoir, mais pas à long terme, car elle ne génère pas de fidélité envers les hommes politiques ou les partis.

Mots-clés: Bolsa Família; élections; Lula 